\title{
man \\ ADFIST: Adaptive Dynamic Fuzzy Inference System Tree Driven by Optimized Knowledge Base for Indoor Air Quality Assessment
}

\author{
Jagriti Saini $^{1, *(\mathbb{D})}$, Maitreyee Dutta ${ }^{1}$ (D) and Gonçalo Marques ${ }^{2, *(D)}$ \\ 1 National Institute of Technical Teacher's Training and Research, Chandigarh 160019, India; \\ d_maitreyee@yahoo.co.in \\ 2 ESTGOH, Polytechnic of Coimbra, Rua General Santos Costa, 3400-124 Oliveira do Hospital, Portugal \\ * Correspondence: jagritis1327@gmail.com (J.S.); goncalosantosmarques@gmail.com (G.M.)
}

check for

updates

Citation: Saini, J.; Dutta, M.;

Marques, G. ADFIST: Adaptive

Dynamic Fuzzy Inference System

Tree Driven by Optimized

Knowledge Base for Indoor Air

Quality Assessment. Sensors 2022, 22,

1008. https://doi.org/10.3390/

s22031008

Academic Editor:

Periklis Chatzimisios

Received: 13 November 2021

Accepted: 25 January 2022

Published: 28 January 2022

Publisher's Note: MDPI stays neutral with regard to jurisdictional claims in published maps and institutional affiliations.

Copyright: (C) 2022 by the authors. Licensee MDPI, Basel, Switzerland. This article is an open access article distributed under the terms and conditions of the Creative Commons Attribution (CC BY) license (https:// creativecommons.org/licenses/by/ $4.0 /)$.

\begin{abstract}
Air quality levels do not just affect climate change; rather, it leaves a significant impact on public health and wellbeing. Indoor air pollution is the major contributor to increased mortality and morbidity rates. This paper is focused on the assessment of indoor air quality based on several important pollutants $\left(\mathrm{PM}_{10}, \mathrm{PM}_{2.5}, \mathrm{CO}_{2}, \mathrm{CO}, \mathrm{tVOC}\right.$, and $\left.\mathrm{NO}_{2}\right)$. These pollutants are responsible for potential health issues, including respiratory disease, central nervous system dysfunction, cardiovascular disease, and cancer. The pollutant concentrations were measured from a rural site in India using an Internet of Things-based sensor system. An Adaptive Dynamic Fuzzy Inference System Tree was implemented to process the field variables. The knowledge base for the proposed model was designed using a global optimization algorithm. However, the model was tuned using a local search algorithm to achieve enhanced prediction performance. The proposed model gives normalized root mean square error of $0.6679,0.6218,0.1077,0.2585,0.0667$ and 0.0635 for $\mathrm{PM}_{10}, \mathrm{PM}_{2.5}, \mathrm{CO}_{2}, \mathrm{CO}, \mathrm{tVOC}$, and $\mathrm{NO}_{2}$, respectively. This approach was compared with the existing studies in the literature, and the approach was also validated against the online benchmark dataset.
\end{abstract}

Keywords: indoor air quality; fuzzy inference system; pollution; optimization; public health

\section{Introduction}

The Environmental Protection Agency (EPA) defines indoor air quality (IAQ) as the quality of air within building premises or closed rooms that can leave a significant impact on occupant health, comfort, and productivity levels [1]. It is already proven that human activities, industrial operations, and increasing traffic on roads are the major factors behind the deterioration in the environment [2]. Along with several outdoor sources, IAQ is affected by inadequate thermal comfort levels due to high humidity and temperature in the closed structures, inadequate ventilation management, hazardous building materials, and day-to-day human activities [3]. The rising concentrations of harmful pollutants within indoor environments is further linked to the deteriorating health of building occupants, especially elderly, infants, persons with disabilities, and household women, as they spend most of their time indoors [4-6]. Therefore, it is crucial to understand all aspects of indoor air pollution (IAP) and its impact on public health, while identifying potential solutions for IAQ management in the closed structures.

As per a survey representing almost 30,000 institutions from the United States, it was observed that environmental air quality control is the prime requirement of the country as it is causing major damage to the health and wellbeing of the people [7]. IAP is directly associated with rising cases of morbidity and mortality in both developed and developing countries, as it is directly linked to several acute and chronic diseases $[4,8]$. The shortterm and long-term health effects are reported depending upon the level and duration of exposure to harmful pollutants. The symptoms linked to short-term health effects include 
wheezing, eye/skin irritation, and nasal congestion; however, they are preventable [9]. On the other side, long-term health effects are respiratory infections [10], pulmonary tuberculosis [11], adverse pregnancy outcomes [12], asthma [13], chronic bronchitis [14], cancer [15], and heart disease [16]; the patients may report them after repeated and long periods of exposure.

There are a variety of pollutants that affect the health of building occupants inside homes, offices, cafes, schools, hospitals, and shopping malls. Due to the increasing transportation activities, industrial activities, and infrastructure, the ambient air pollution levels are increasing with a sharp curve, which ultimately accounts for the decaying IAQ levels as well [17]. Other than this, there are several potential sources of pollutants in the indoor environment at rural and urban buildings. Rural homes experience decay in air quality levels due to repeated use of coal, cow dung, wood, and kerosene for heating and cooking purposes [5]. Unventilated homes in urban areas reduce the circulation of healthy air for breathing [18]. The list of harmful pollutants that affect the building environment includes particulate matter $(\mathrm{PM})$, carbon dioxide $\left(\mathrm{CO}_{2}\right)$, carbon monoxide $(\mathrm{CO})$, sulphur dioxide $\left(\mathrm{SO}_{2}\right)$, nitrogen oxides $\left(\mathrm{NO}_{\mathrm{x}}\right)$, volatile organic compounds (VOCs), ozone, radon, heavy metals, bioaerosols, and antioxidants [3].

IAQ management is critical for better public health outcomes. Therefore, field experts and researchers from the past several years are working in this direction to identify reliable solutions. Numerous researchers are using the Internet of Things (IoT) and Wireless Sensor Network (WSN) based technologies to design IAQ monitoring solutions to assess air quality in the building premises. Xie et al. [19] designed an artificial neural network (ANN) based IAQ prediction system while focusing on six IAQ variables and three thermal comfort parameters. They used occupant symptom metric to measure IAQ levels. Backpropagation based feed-forward network with variable learning rate and momentum term was used for ANN modelling. Tagliabue et al. [20] designed an IoT based system to gather IAQ data from educational building at University of Brescia. The main goal of this work was to regulate the HVAC system along with the opening and closing patterns of lab windows to enhance IAQ levels in the premises that could further enhance the learning performance of occupants. The proposed methodology suggests efficient use of ANN for triggering enhanced ventilation rate control via IoT communication protocol. Ahn et al. [21] used deep learning based models with IAQ sensor data for estimating atmospheric changes. They used two deep learning methods: gated recurrent unit (GRU) and long-short term memory (LSTM) network for time series data analysis. The optimal time step search approach proposed by authors in this study presented best learning performance in comparison to conventional models.

The authors have already published comprehensive [22] and systematic reviews [23,24] focusing on existing advancements in the field of IAQ monitoring and assessment while highlighting the need, challenges, and future scopes in this important field of research to provide insights to the related work in this field. Other than this, several studies have also been published on the development of prediction systems based on neural networks, machine learning, and deep learning approaches to assist building occupants with a prior indication of harmful pollutant concentrations. Furthermore, the authors have published a systematic review to highlight the contribution of existing researchers in the field along with the gaps in literature [25].

The main objective of this paper is to present an Adaptive Dynamic Fuzzy Inference System Tree (ADFIST) based approach to predict potential indoor air pollutants from the target sites. The authors have collected real-time data from four different rural and urban sites on six important IAQ parameters, including $\mathrm{PM}_{10}, \mathrm{PM}_{25}, \mathrm{CO}_{2}, \mathrm{CO}, \mathrm{NO}_{2}$, $\mathrm{tVOCs}$, along with two crucial thermal comfort parameters-temperature and humidity. An approach consisting of aggregating multiple fuzzy inference systems (FIS) with a specific set of inputs considering their correlation with the response variable was used, and the rule learning process was further optimized using particle swarm optimization (PSO). Ultimately, the model was tuned using a pattern search algorithm to achieve enhanced prediction accuracy 
so that the proposed system can be implemented in real-time scenarios to avoid critical consequences associated with poor IAQ levels. The proposed model is called dynamic because it uses a dynamic combination of input features as per the selected response variable for prediction. The adaptive nature of the model corresponds to its rule learning behaviour which is optimized by PSO and Pattern Search to ensure a unique set of rules at every stage for different input-output combinations.

The performance of the proposed method was analysed through normalized rootmean-square error (NRMSE), normalized mean square error (NMSE), coefficient of determination $\left(\mathrm{R}^{2}\right)$, and mean absolute percentage error (MAPE). In this paper, Section 2 provides details about the experimental design of an IoT-based monitoring system, real-time parameter collection from the field, and data pre-processing; Section 3 includes detailed information about methodology and methods. Furthermore, Section 4 presents the results and discussion about model performance in terms of the above-mentioned performance indicators, and finally, the conclusion is presented in Section 5.

\section{Materials and Methods}

Several primary and secondary pollutants affect IAQ levels. However, their concentration varies depending upon the geographical area under consideration. The authors focused on collecting real-time data on potential pollutants from a rural site in India. The preferred IAQ parameters for this study were $\mathrm{PM}_{10}, \mathrm{PM}_{2.5}, \mathrm{CO}_{2}, \mathrm{CO}, \mathrm{NO}_{2}, \mathrm{tVOCs}$, and along with these, two major thermal comfort parameters were also monitored: temperature and humidity. These eight parameters were selected out of many other crucial IAQ and thermal comfort parameters only after studying the environmental conditions of the target geographical area. Recommendations from air pollution experts in the area were also taken regarding the selection of parameters to address the field IAQ concerns. The hardware monitoring system was installed in the kitchen area of a home located in a rural village of Himachal Pradesh, where traditional heating and cooking practices are followed. The map of the selected monitoring site is provided in Figure 1. The major sources of pollution at this site are the fireplace that involves the burning of wood, cow dung, kerosene, dry grass, and traditional cooking practices. The detailed information on monitoring system design and parameter collection is provided in the subsections below.

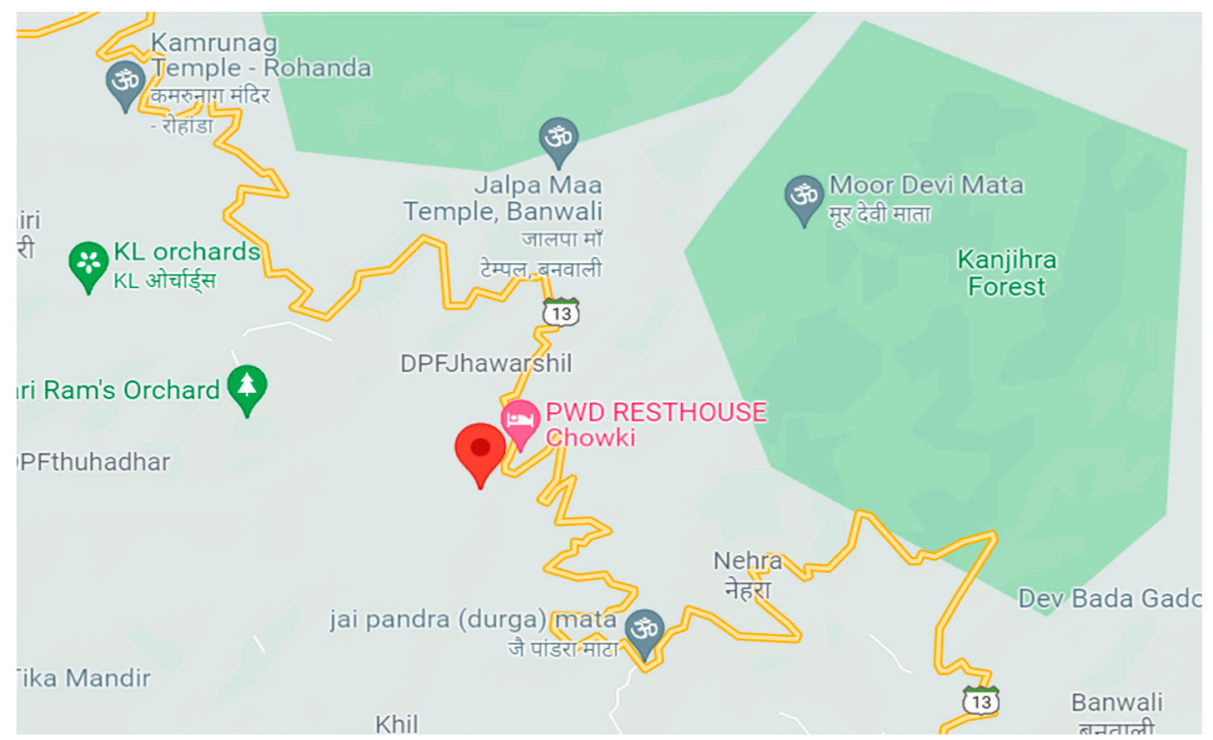

Figure 1. Monitoring site location displayed using Google Maps.

\subsection{Monitoring System Design}

The design of the proposed IAQ monitoring system was based on IoT technologies. The authors used four different IAQ sensor modules along with an Arduino Uno microcontroller and ESP8266 communication module to collect information on concentration, eight 
different focus IAQ, and thermal comfort parameters. CCS811 sensor was preferred for measuring $\mathrm{CO}_{2}$ and $\mathrm{tVOC}$ concentration, SDS011 sensor provided field data on $\mathrm{PM}_{10}$ and $\mathrm{PM}_{2.5}$ parameters; whereas Grove-Air quality sensor v1.3-MP503 module was used to measure the concentration of $\mathrm{NO}_{2}$ and $\mathrm{CO}$ from target sites. Other than this, the DHT11 sensor module was used for measuring thermal comfort parameters (temperature and humidity). Table 1 provides manufacturer specifications for all these sensor modules. The above-mentioned sensors were connected to the Arduino Uno microcontroller for collecting real-time data from the target field environment. Furthermore, the ESP8266 module was used as a gateway to transfer field data to the centralized online platform. ThingSpeak open-source platform was used for collecting real-time data from the target rural site. Numerous competitive sensor modules in the market can be used to create IoT-based IAQ monitoring systems. The main focus of the authors was to design a cost-effective system while ensuring calibrated data collection. The overall cost of a complete hardware monitoring system in this study turned out to be USD 81.60, including the estimated cost of Arduino Uno (USD 6.73), ESP8266 gateway unit (USD 1.35), and miscellaneous items such as wires and breadboards (USD 3.37).

Table 1. Manufacturer specifications for sensors used to design IoT based hardware module.

\begin{tabular}{|c|c|c|c|c|c|}
\hline Sensor Name & Manufacturer & Type of Sensor & Measurement Parameter & Typical Range & $\begin{array}{l}\text { Cost of Sensor/Unit } \\
\text { (US Dollars) }\end{array}$ \\
\hline CCS811 & SparkFun & Digital Sensor & $\mathrm{CO}_{2}, \mathrm{tVOC}$ & $\begin{array}{l}0-1187 \text { ppb (tVOC); } \\
400-8192 \text { ppm }\left(\mathrm{CO}_{2}\right)\end{array}$ & $\$ 24.28$ \\
\hline SDS011 & Nova Fitness & Laser Sensor & $\mathrm{PM}_{10}, \mathrm{PM}_{2.5}$ & $0.0-999.9 \mu \mathrm{g} / \mathrm{m}^{3}$ & $\$ 31.70$ \\
\hline $\begin{array}{l}\text { Grove-Air quality } \\
\text { sensor v1.3-MP503 }\end{array}$ & Seed Studio & Digital Sensor & $\mathrm{CO}, \mathrm{NO}_{2}$ & NA & $\$ 12.82$ \\
\hline DHT11 & Aosong MPN & $\begin{array}{l}\text { Negative Temperature } \\
\text { Coefficient (NTC) }\end{array}$ & Temperature, Humidity & $\begin{array}{l}0{ }^{\circ} \mathrm{C} \text { to } 50{ }^{\circ} \mathrm{C} ; \\
20 \% \text { to } 90 \%\end{array}$ & $\$ 1.35$ \\
\hline
\end{tabular}

The authors used factory-calibrated sensor units to ensure reliable real-time data collection from the field environment. However, the authors also preferred conducting field reliability tests before deploying sensors in the field. For the DHT11 sensor, the reliability was tested in the laboratory against a standard instrument (Honeywell TM00X), whereas for the remaining three sensors, the manufacturer specified procedures were conducted to ensure stable performance. The hardware monitoring system was set to provide readings on-field pollutant concentrations after every $5 \mathrm{~min}$, and the total duration of measurements was six months from 1 January 2021 to 30 June 2021. The general architecture of IoT based IAQ monitoring system is given in Figure 2.

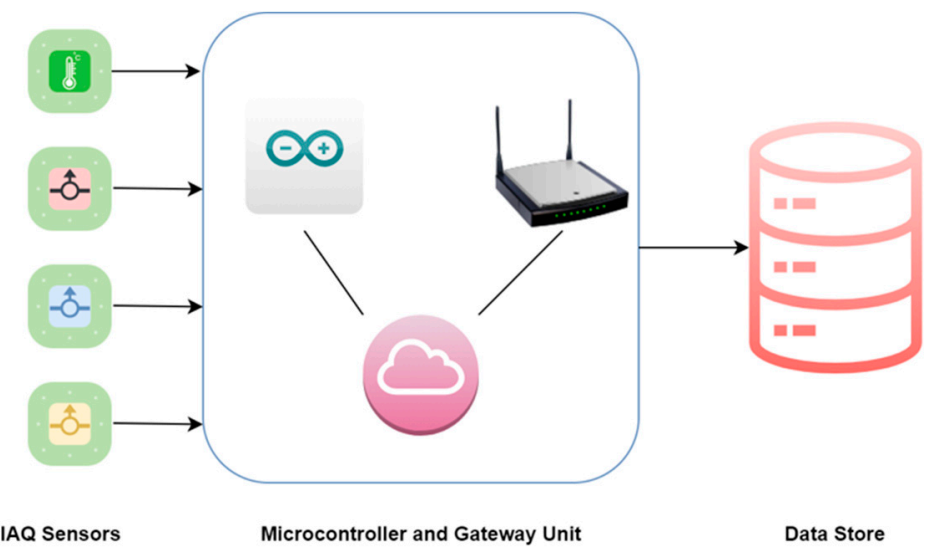

Figure 2. Hardware monitoring system architecture.

\subsection{Data Pre-Processing}

The real-time data stored on the ThingSpeak channel was exported in the form of an excel file. It was expected to receive 51,840 samples from the field within the given 
duration of 6 months. However, due to system failures, maintenance issues, and other field-associated errors, a total of 42,051 samples were recorded with an $18.8 \%$ error rate. The dataset containing eight different IAQ and thermal comfort parameters was first analyzed using boxplots Figure S1 (Supplementary Materials), and considerable amounts of samples were found outside the lower and upper quartile ranges. The samples beyond the outer fence of the boxplot are called extreme outliers, and they are required to be removed to increase statistical power and to reduce variability in data. Considering the recommendations provided by existing researchers in the literature, authors preferred using the Interquartile range method for outlier removal [26,27]. In this method, Q1 (first quartile) represents the 25 percentiles, cutting off the lowest 25\% of data, and Q3 (third quartile) cuts off the highest $25 \%$ of the data while giving the intermediate values of the data distribution at the output. The formula for extracting the middle half of data while removing outliers above and below the quartile range is given by Equation (1) [28].

$$
I Q R=Q 3-Q 1
$$

After outlier removal, the data containing 30436 samples was processed further to test the presence of missing values. The dataset had $22.3 \%$ missing values. As field data does not contain nominal attributes, the authors decided to use the mean imputation method for missing value imputation [29,30]. In this method, the missing data cells are filled with the mean value of the respective attribute. As the data samples from the field are collected every $5 \mathrm{~min}$, it is necessary to use a standard averaging method to summarise data readings. Therefore, the next step in the data pre-processing was to apply mean-hour reduction, which provided 3695 samples at the output. The statistical information in terms of mean, std, min, max, and quartile ranges of the dataset is presented in Table 2. These samples were further utilized for prediction model design.

Table 2. Statistical information about measured and pre-processed field parameters.

\begin{tabular}{ccccccccc}
\hline & Temp & Hum & $\mathbf{P M}_{\mathbf{2 5}}$ & $\mathbf{P M}_{\mathbf{1 0}}$ & $\mathbf{C O}$ & $\mathbf{N O}_{\mathbf{2}}$ & $\mathbf{C O}_{\mathbf{2}}$ & $\mathbf{t V O C}$ \\
\hline Count & 3695.00 & 3695.00 & 3695.00 & 3695.00 & 3695.00 & 3695.00 & 3695.00 & 3695.00 \\
Mean & 29.900 & 53.921 & 124.117 & 144.724 & 67.477 & 67.088 & 745.133 & 52.780 \\
Std & 1.915 & 9.841 & 200.603 & 229.093 & 8.103 & 8.156 & 249.922 & 39.707 \\
Min & 22.100 & 23.750 & 1.736 & 2.337 & 38.000 & 36.000 & 400.000 & 0.000 \\
$25 \%$ & 29.690 & 48.916 & 8.608 & 13.051 & 62.833 & 62.333 & 566.090 & 24.784 \\
$50 \%$ & 29.900 & 53.921 & 20.381 & 30.541 & 67.477 & 67.088 & 735.166 & 50.416 \\
$75 \%$ & 31.250 & 60.818 & 124.117 & 144.724 & 72.916 & 72.727 & 770.606 & 55.958 \\
Max & 33.218 & 79.000 & 999.90 & 1378.90 & 93.500 & 93.714 & 1544.00 & 203.00 \\
Variance & 3.668 & 96.825 & $40,230.93$ & $52,469.67$ & 65.644 & 66.503 & $62,444.47$ & 1576.28 \\
\hline
\end{tabular}

The literature states that environmental data are random in nature due to cyclic variations, seasonal variations, and irregular movements [31-33]. Other than this, due to the use of low-cost sensors, a considerable amount of measurement uncertainty and variability is also introduced to the field data [34]. Therefore, the authors decided to use a FIS to process the field data that is fuzzy in nature. The data was analysed on the basis of correlation between features. Figure 3 shows a correlation plot based on the Pearson Correlation method to describe the general distribution of data. The information obtained from correlation analysis will be further utilized in designing DFIST for IAQ prediction. After analysing the correlation response of variables, the authors used the $\mathrm{k}$ fold cross-validation approach for data splitting, as suggested by [35,36]. The Naïve-Bayes based cross-validation was used to split data with $20 \%$ holdout on a total of 3695 samples; as a result, 2956 samples were left for training data and 739 for validation data [37-39]. The available dataset was further utilized for prediction model training and validation performance assessment. 


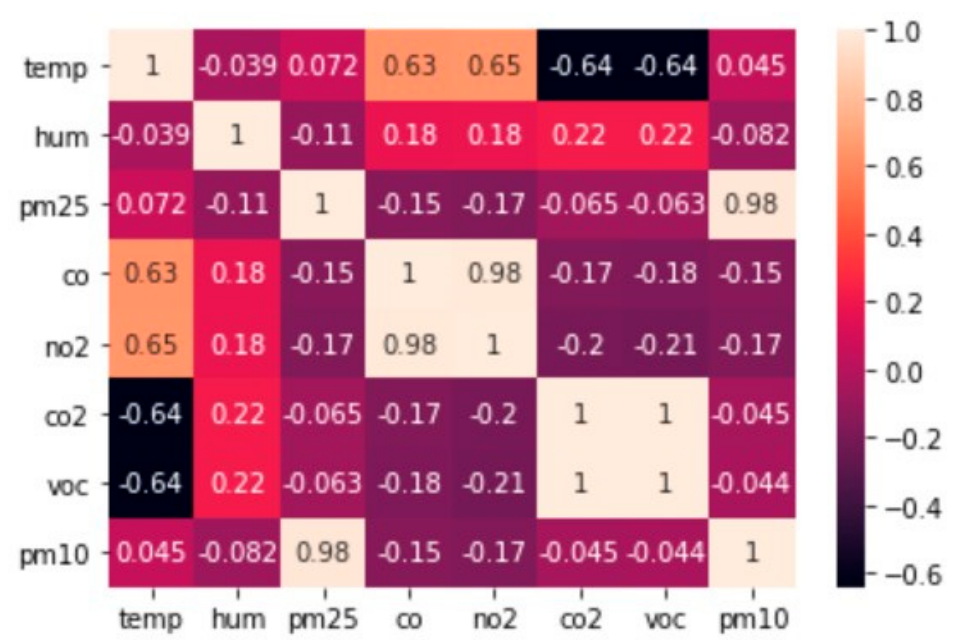

Figure 3. Pearson correlation between parameters.

\subsection{Parameter Classifications}

The Environment Pollution Agency (EPA) has already defined air quality levels based on their negative impact on public health. We followed EPA guidelines to identify and evaluate the IAQ parameters according to their safe and unsafe limits. Based on the available information in the literature. Consequently, the IAQ parameter ranges were defined using five different categories as follows:

a. Good: This is considered appropriate to perform normal day-to-day activities.

b. Moderate: Indoor activities can be performed; however, children and elderly people may be affected.

c. Unhealthy: Indoor activities must be avoided; especially for children and adults with respiratory health issues.

d. Poor: Sensitive groups may experience serious discomfort. In this situation, it is necessary to implement pollution emission controlling measures on a priority basis.

e. Hazardous: Recommendations for following serious measures to protect the health of the building occupants by using adequate ventilation and air quality purification measures.

These threshold levels are further used in model training to help to make decisions about the forecasting values for the respective response variables.

\section{Methods}

Decaying IAQ levels in the residential and commercial buildings is a matter of concern for occupant health and wellbeing. Adequate technological interventions can ensure promising solutions for IAP management and control. In Section 2, details about the development of IoT based monitoring system has been discussed. It is further possible to integrate the potential of Artificial Intelligence (AI) to perform real-time assessment and control of environmental factors. As data collected from the field environment has higher variability and is fuzzy in nature, authors preferred using the potential of fuzzy systems to design a prediction system to address the concerns. The concept of fuzzy logic was first proposed by Lotfy A. Zadeh in the mid-1960s [40]. A fuzzy set is defined as the class of objects having different degrees of membership, and each set in fuzzy logic systems is characterized by a unique set of membership functions. The degree of membership for each object in fuzzy systems can range between 0 and 1 . The main advantage of fuzzy logic is that the concept is influenced by human reasoning and the degree of belongingness of object to the class is measured in proportions. There are four main elements of a fuzzy logic architecture: fuzzification, inference engine, rule base, and defuzzification: 
- The Fuzzification step converts crisp inputs into fuzzy systems. These crisp inputs are generally the data measured by sensors that are required to be passed to a fuzzy control system for further processing.

- Rule base plays an important role in fuzzy decision-making. Rule base or knowledge base is basically a set of in-then conditions developed from expert knowledge or field conditions.

- $\quad$ The inference engine defines the degree of match between fuzzy input and knowledge base. It decides which rules must be implemented to achieve the desired output as per the given input.

- Defuzzification is the process of converting fuzzy sets back into crisp values that can be further used in real-life environments.

A simple fuzzy logic system is required to have $\mathrm{m}^{\mathrm{n}}$ number of rules; where $\mathrm{m}=$ the number of membership functions assigned per input variable and $n=$ the total number of inputs [41,42]. The available field IAQ data have seven input variables and one output variable. For instance, on assigning five membership functions per input variable to depict EPA-based pollutant concentration levels, the system may need to have $5^{(7)}=78,125$ number of rules. It is quite difficult to design such a huge number of fuzzy rules manually and the process is prone to errors. Furthermore, a system with such a large number of rules is likely to have high computational complexity. Moreover, the practical realization of such a system is challenging. Therefore, the authors decided to use the hierarchical structure for fuzzy system design to forecast IAQ response variables [43,44]. FIS can provide good reasoning for the pollutant concentrations while processing field variables with their unique scales. The hierarchical structure of FIS makes use of $\mathrm{km}^{\mathrm{n}}$ number of rules; where $\mathrm{k}=$ number of FIS used in the system design, $\mathrm{m}=$ number of membership functions per input variable, and $\mathrm{n}=$ number of input variables [41,42]. In this tree form, every FIS module takes two inputs only, and numbers of FIS modules are arranged in a cascaded manner to accommodate all input variables for obtaining final forecasting outcomes. Therefore, the total number of rules required for designing a hierarchal FIS structure with seven input variables, five membership functions per input, and six FIS modules to accommodate 7 inputs at different levels will be $6 \times 5^{(2)}=150$ only. Therefore, the computational complexity and design issues for FIS based forecasting system can be resolved with ease. Furthermore, the hierarchal approach helps to evaluate input features based on their correlation with the response variables so that the prediction accuracy can be enhanced. In the second phase, PSO has been utilized to optimize the rule learning process, and in the final phase, the network is tuned using a pattern search algorithm. The entire process is explained in detail in the below sub-sections.

\subsection{Fuzzy Inference System Tree}

FIS makes use of fuzzy logic to design an expert system that can perform a reasoning process with the mapping of several input vectors to a single output. There are two different types of FIS: Mamdani and Sugeno. For the proposed study, the authors used Mamdani FIS due to its simplest structure and enhanced freedom to map antecedents to consequents with fuzzy membership $[45,46]$. In the first phase, an input assessment model is designed using fuzzy membership functions. The pollutant concentration levels are evaluated based on their impact on human health, and the ranges are divided into five different categories as defined in Section 2.3. However, the thermal comfort parameters (temperature and humidity) are defined using three different categories: good/low, moderate, and high. In this work, authors used triangular membership functions for defining parameter ranges recommended by [47] to transform respective input real-valued parameter ranges into fuzzy values ranging between 0 and 1 . The mathematical expression for triangular membership functions is defined in Equation (2).

$$
\mu(x, a, b, c)=\max \left\{\min \left\{\frac{x-a}{b-a}, \frac{c-x}{c-b}\right\}, 0\right\}
$$


where $x=$ input pollutant concentration, $a, b, c$ are parameter ranges defined by membership functions. They usually vary as per the defined limits of the respective pollutants under EPA guidelines. After assigning membership functions to each concentration level, the reasoning process can be implemented with the help of specific operators. Before developing FIS, it is necessary to develop an understanding of fuzzy operators used in the reasoning process. In this work, the authors have used two main fuzzy operators: Union and Intersection, which represent OR \& AND operation, respectively [48]. The mathematical representations of these operators are given in Equations (3) and (4).

$$
\begin{gathered}
\text { Union (OR) }: \mu_{A \cup B}(x)=\max \left\{\mu_{A}(x), \mu_{B}(x)\right\} \\
\text { Intersection (AND) }: \mu_{A \cap B}(x)=\min \left\{\mu_{A}(x), \mu_{B}(x)\right\}
\end{gathered}
$$

In terms of IAQ assessment, FIS models are more useful due to their subjectivity handling [40]. The fuzzy logics make it easier to interpret the existing knowledge while mapping to a level of uncertainty to specific evaluations on the fuzzy scale. To ensure accurate prediction of parameter concentrations, it is necessary to access all IAQ scenarios carefully while presenting hazardous concentrations with accurate descriptions. Fuzzy reasoning provides better opportunities to address pollutant concentrations with their unique impact on human health. The knowledge/rule base can be designed accordingly as per expert guidelines on air quality situations. For instance, if the temperature is low and $\mathrm{PM}_{2.5}$ is good, then $\mathrm{PM}_{10}$ is good. Different parameter concentrations can be linked to each other based on the correlation to each other, guidelines provided by air quality experts, and the studies already published in the literature $[49,50]$. The fuzzy reasoning for different pollutant concentration levels, represented by different membership function ranges, can be given as below:

Sample Rule 1: If Temp is low and $\mathrm{PM}_{2.5}$ is good, then $\mathrm{PM}_{10}$ is good.

Sample Rule 2: If Temp is moderate and $\mathrm{PM}_{2.5}$ is moderate, $\mathrm{PM}_{10}$ is moderate.

The decision regarding the impact of rule antecedent combination on consequent conditions is made on the basis of existing research and expert guidelines [40,51,52]. When the rule contains the AND operator between different antecedent parameters, the combination can be evaluated jointly using the min operator. For example, if the fuzzy value for temperature low is equal to 0.1 and for $\mathrm{PM}_{2.5}$ moderate is 0.3 , then the min operator for this condition with $\mathrm{PM}_{10}$, can, consequently, be presented by Equation (5).

$$
\mu_{P M 10}=\min \{0.1,0.3\}=0.1
$$

The rule base is further aggregated using the max operator to receive output value [48] After computing the individual rules, the superimposed area of all rule outputs indicates the final outcome of the reasoning-based evaluations [48]. The membership functions for input features and with $\mathrm{PM}_{10}$ as response variable are shown in Figure 4. At the final stage of the FIS, a defuzzification method is used to obtain real-time outputs for the field-based study. The defuzzification method used in this study is Centroid Function, and the formula for calculating defuzzified values out of aggregated values is given in Equation (6) [53]. This method provides the centre of the area under the curve as per the output membership function [54]. This method returns a value using the restrictions defined with input membership functions ranging from good to hazardous.

$$
x^{*}=\frac{\int \mu_{c_{m}}(x) \cdot x^{\prime} d x}{\int \mu_{c_{m}}(x) d x}
$$



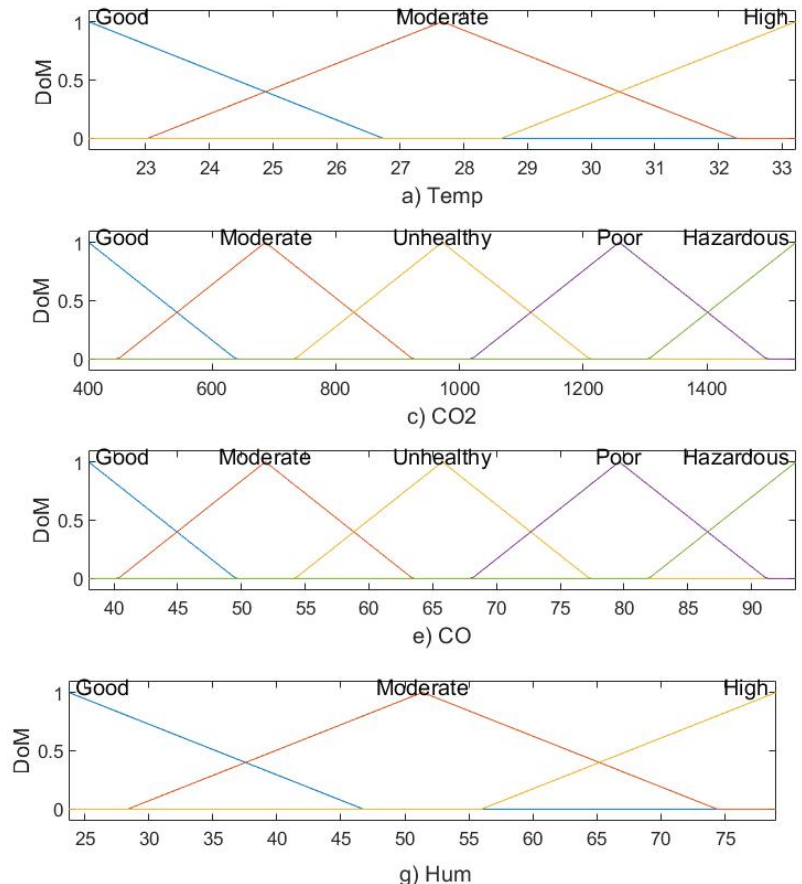
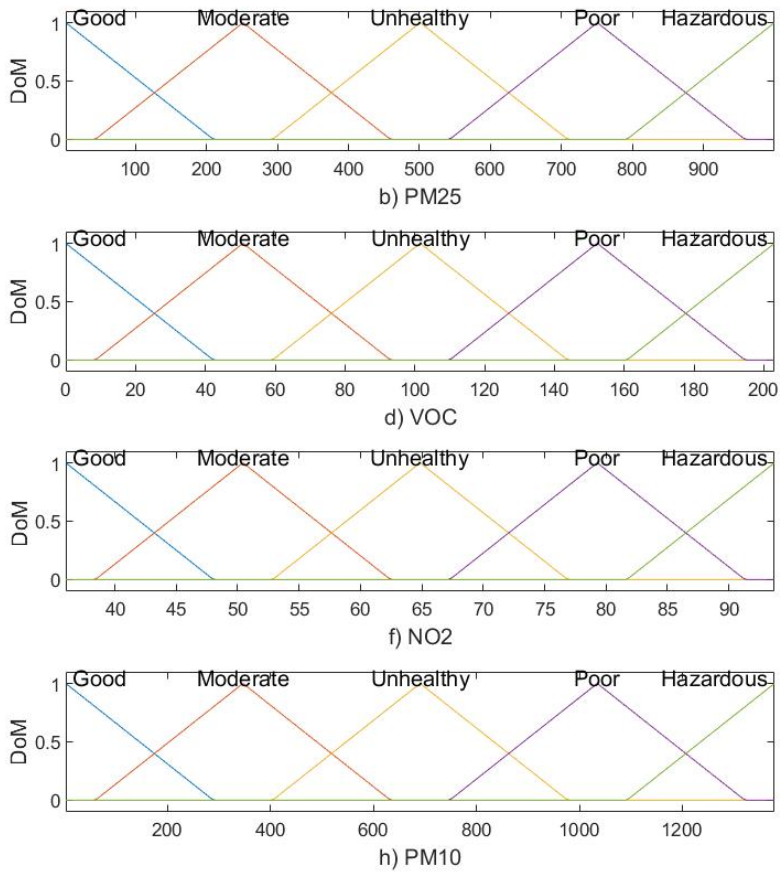

Figure 4. Membership functions for air quality parameters: (a) Temp, (b) $\mathrm{PM}_{2.5}$, (c) $\mathrm{CO}_{2}$, (d) $\mathrm{tVOC}$, (e) $\mathrm{CO}$, (f) $\mathrm{NO}_{2}$, (g) Hum and (h) $\mathrm{PM}_{10}$.

The system robustness usually depends upon the number of rules in the FIS. However, instead of designing the rules manually for all input parameters, the authors used PSO to the optimized rule learning process.

\subsection{Particle Swarm Optimization}

PSO is a global optimization algorithm that is inspired by swarm intelligence [55]. In this approach, the particle is used to indicate the swarm with the two necessary parameters: position and velocity [56]. All particles in the group work over the same principles, under similar working conditions, to find the best personal and best overall fitness values. The objective function is usually problem-dependent, and several iterations are performed to achieve good results for the target problem space [57]. Each particle has a specific velocity and position vector in the problem space, and it is updated after every learning cycle to achieve the best results. The new velocity and position values are obtained as per Equations (7) and (8), respectively [56].

$$
\begin{gathered}
V_{i}(t+1)=w V_{i}(t)+c_{1} r_{1}\left(P_{\text {pbest }}(t)-P_{i}(t)\right)+c_{2} r_{2}\left(P_{\text {gbest }}(t)-P_{i}(t)\right) \\
P_{i}(t+1)=P_{i}(t)+V_{i}(t+1)
\end{gathered}
$$

where $P_{i}$ represents position vector and $V_{i}$ represents velocity vector in the problem space. Furthermore, $c_{1}$ and $c_{2}$ are acceleration constants, $r_{1}$ and $r_{2}$ are random numbers distributed between 0 and 1 . Inertia weight $(w)$ is utilized as a control parameter to adjust the impact of prior velocity values on the current velocity value [56]. As PSO is a global search algorithm, it has the ability to produce a relevant knowledge base for the FIS when employed at the rule learning stage. The general algorithm for PSO can be given in Algorithm S1 (Supplementary Materials) [55]:

For the given problem, the parameter initialization was carried out as follows: $w=1$, $c_{1}=1, c_{2}=2$, population size $=100$ and the number of iterations at PSO rule learning stage were kept 150 . To optimize the rule learning process for the FIS system, the authors first designed the hierarchical structure of FIS to process input features as per their correlation with the response variable. Consequently, the membership functions were defined as 
per the air quality concentration guidelines, and the values were assigned to individual parameters. Finally, the FIS system was allowed to learn rules with the PSO algorithm. For the current problem, each particle is adjusted to achieve model rules corresponding to input membership functions. Each particle represents the potential best solution, and it is updated every time using Equations (7) and (8) to achieve global best fitness value. Figure 5 represents the general flow of the FIS system with PSO as a knowledge base optimization algorithm.

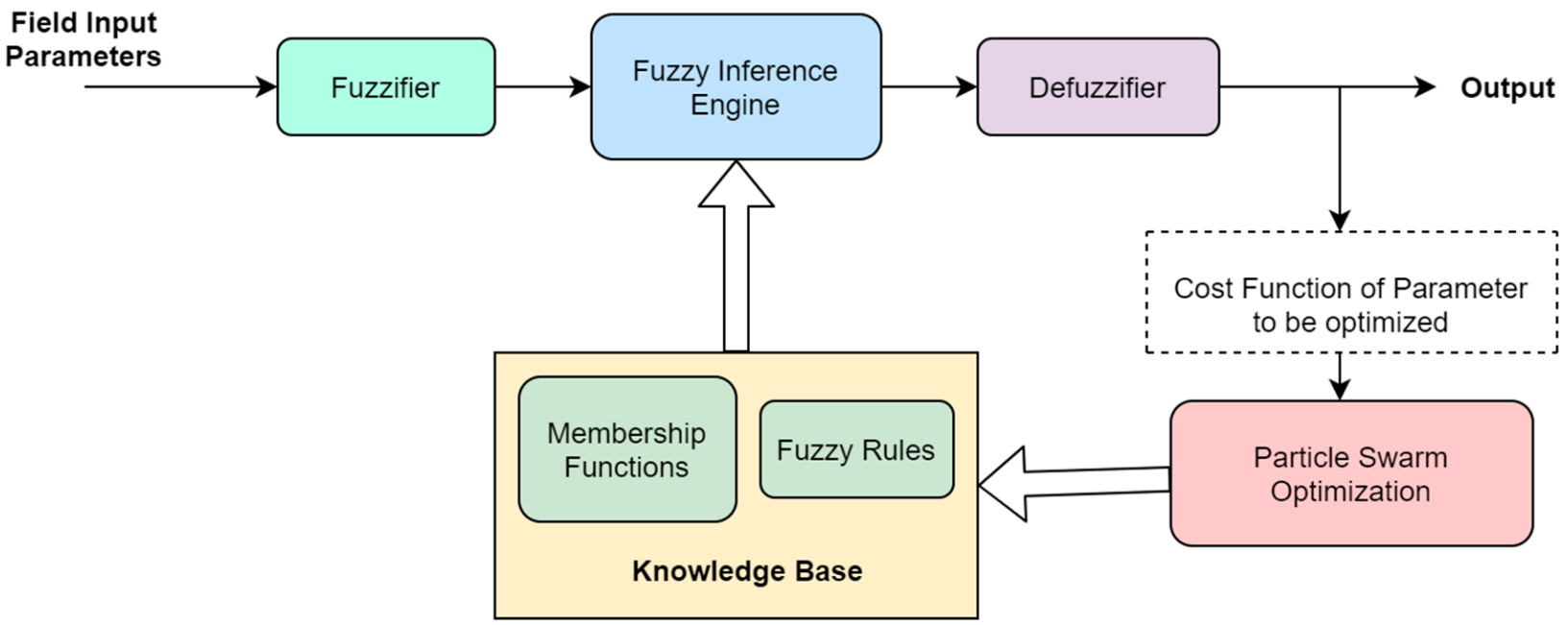

Figure 5. General flow of FIS system with PSO rule learning.

\subsection{Pattern Search Algorithm}

Pattern search or direct search is a derivative-free search algorithm that belongs to the numerical optimization methods [58]. It does not require a gradient to achieve the best value for the objective function. It is widely used for identifying the best match or the solution with the lowest error value in the problem space. This method is widely used for multidimensional analysis [59]. For the current experimental analysis, the pattern search algorithm is applied at the final model tuning stage to enhance the prediction accuracy. The number of iterations at this stage was kept 100, and the focus tuning parameters were rule base, inputs, and the model output. The general steps for pattern search algorithm are given in Algorithm S2 (Supplementary Materials) [58]. This algorithm works with an initial guess at solution $\mathrm{x}_{0}$, and the initial choice for the step length parameter is generally $\Delta_{0}>0$.

\subsection{ADFIST Implementation}

To design the proposed ADFIST model, the authors arranged multiple FIS in the form of an incremental tree. As the ADFIST is desired to provide a prediction for all IAQ parameters, a dynamic approach was followed for setting up input and output variables for particular instances. As there are seven input features, we have aggregated six FIS systems to accommodate all inputs; however, two inputs were given at one stage. The reason to use only two input and single output FIS per stage is to limit the number of rules that could further reduce the computational complexity at every stage [60]. The decision about the organization of input parameters at every stage was made based on the correlation between features and the response variable, as shown in Figure 3 [61-63]. In the first stage, the correlation between the response variable and all input features was tested, and then the correlation between features was analyzed. The general structure of DFIST is given in Figure 6 with 6 FIS at different stages, feeding two input parameters to one FIS module. 


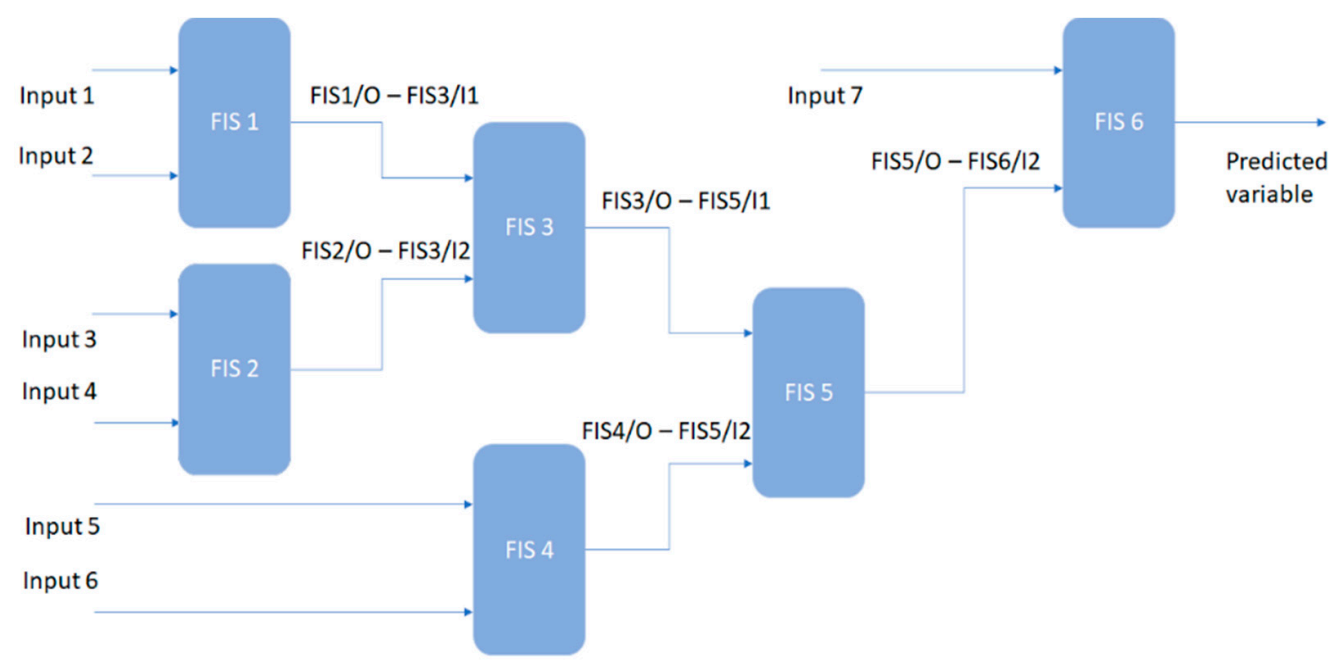

Figure 6. General architecture of DFIST model.

For instance, when $\mathrm{PM}_{10}$ was selected as a response variable, among all input features, $\mathrm{PM}_{2.5}$ presented maximum correlation (0.98). However, among thermal comfort parameters, temperature provided a positive correlation of 0.045 . Therefore, these two features were used at the first stage of the FIST and were fed to FIS1. For the next stage, as we have all features with negative correlation, the combination for FIS2 was decided based on the features that show the highest correlation with each other. Therefore, $\mathrm{tVOC}$ and $\mathrm{CO}_{2}$ were connected to FIS2, and then the output of FIS1 and FIS2 were combined at FIS3. Furthermore, FIS4 was fed with $\mathrm{CO}$ and $\mathrm{NO}_{2}$ as they show the highest correlation with each other. The output of FIS3 and FIS4 was combined at FIS5, whose output is further given to FIS6 as the second input, and the first input is given in the form of one remaining thermal comfort parameter (humidity). Finally, the FIS6 provides the desired output of the DFIST, which is considered as a prediction output. Furthermore, the DFIST is made adaptive to the changing input and output combinations with the help of two important optimization algorithms. Therefore, the proposed model is named as Adaptive Dynamic Fuzzy Inference System Tree-ADFIST.

The adaptive behaviour of the model is reported at every stage of the tree as the PSO algorithm is used with every FIS module to optimize the rule learning process with every dynamic combination of input features. The pattern search algorithm is further used to tune the entire system for enhanced prediction performance. The complete architecture of the proposed ADFIST model is given in Figure 7. The full list of rules (in the case of $\mathrm{PM}_{10}$ prediction) for ADFIST is provided in Supplementary Materials.

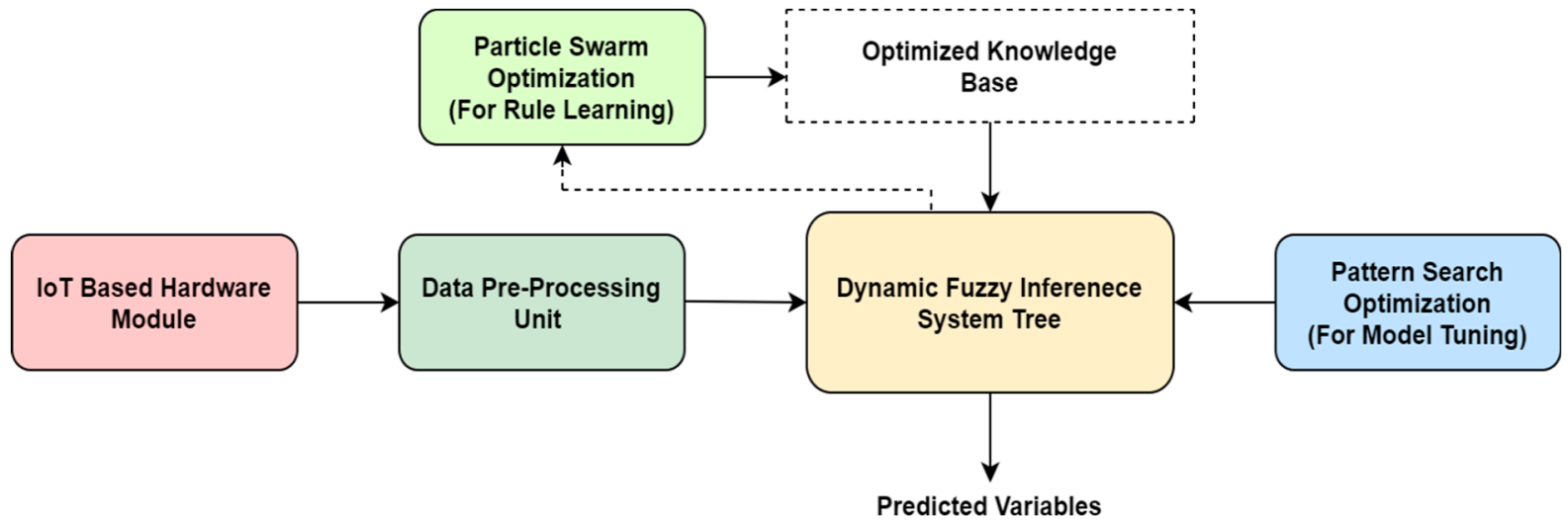

Figure 7. Full system architecture for proposed ADFIST IAQ parameter prediction approach. 
The model performance was further evaluated in terms of NRMSE, NMSE, $\mathrm{R}^{2}$, and MAPE. NRMSE facilitates the assessment of models that work on a dataset with variable scales. It is preferably expressed in percentage and the lower value is usually better as it represents lesser residual variance. The mathematical formula for NRMSE is given in Equation (9). In a similar manner, NMSE is selected for evaluation because of its ability to avoid bias towards models that over-predict or under-predict. As the model accuracy is inversely proportional to NMSE, lower value links to better model performance. The mathematical formula for NMSE is given in Equation (10). Furthermore, $\mathrm{R}^{2}$ is another widely recommended statistical measure to assess the strength of the linear relationship between variables. The formula for the $\mathrm{R}^{2}$ parameter is given in Equation (11); the higher value of this parameter is expected. MAPE is defined as the difference between measured and forecasted values. It is given in percentage and the smaller value of MAPE indicates better forecasts. The mathematical formula for MAPE is given in Equation $(12)[64,65]$.

$$
N R M S E=\frac{\sqrt{\frac{\sum_{i=1}^{N}\left(P_{i}-O_{i}\right)^{2}}{N}}}{\mathcal{M}}
$$

where $P_{i}$ and $O_{i}$ are predictions and observations, respectively; $N$ represents a number of observations, and $\mathcal{M}$ is the mean of the observations.

$$
N M S E=\frac{\overline{\left(C_{o}-C_{p}\right)^{2}}}{\overline{C_{o}} \overline{C_{p}}}
$$

where $C_{o}$ and $C_{p}$ present observed and predicted concentrations, respectively, and the overbar indicates mean over the data sampling points.

$$
R^{2}=\frac{M S S}{T S S}=\frac{T S S-R S S}{T S S}
$$

where MSS represents the model sum of squares, and it can be given as the sum of squares of forecasts from linear equation minus mean of that respective variable. TSS represents the total sum of squares associated with the respective outcome variable.

$$
M A P E=\frac{1}{n} \sum_{t=1}^{n}\left|\frac{A_{t}-F_{t}}{A_{t}}\right|
$$

where $n$ is the number of fitted points, $A_{t}$ is the actual value, and $F_{t}$ is the forecast value.

\section{Results and Discussions}

The design methodology and the approach for implementation of ADFIST are already discussed in Section 3. The proposed model was trained using real-time data obtained from the IoT-based hardware module installed at a rural site. The pre-processing data stages are also explained in Section 2. After obtaining detailed information on field data, and feature correlation, the ADFIST system was fed with the respective input features based on the selection of response variable at a particular instance. The combination of seven external input features and the response variables is given in Table 3.

As shown in Figure 6, the output of FIS1 and FIS2 was combined to fed FIS3, and outputs of FIS3 and FIS4 were further fed to FIS5; however, the output of FIS5 was fed to the second input of FIS6. As the combination of input features and the hierarchy varies as per the selected response variable, the proposed model shows dynamic behaviour to meet the specific requirements of the end-users. For instance, when the end-user requires the model to predict $\mathrm{PM}_{10}$, all the inputs at different levels of the trees will be adjusted as per row 3 of Table 3 . As described in the data pre-processing, the model was trained using 2956 samples; however, 739 (20\%) random samples were kept for model validation. 
Table 3. Input feature arrangements at ADFIST system with respect to the selected response variable.

\begin{tabular}{cccccccc}
\hline \multicolumn{2}{c}{ FIS1 } & \multicolumn{2}{c}{ FIS2 } & \multicolumn{2}{c}{ FIS4 } & FIS6 & Response Variable \\
\hline Input 1 & Input 2 & Input 1 & Input 2 & Input 1 & Input 2 & Input 1 & - \\
Temp & $\mathrm{PM}_{2.5}$ & $\mathrm{CO}_{2}$ & tVOC & $\mathrm{CO}$ & $\mathrm{NO}_{2}$ & Hum & $\mathrm{PM}_{10}$ \\
Hum & $\mathrm{PM}_{10}$ & $\mathrm{CO}_{2}$ & tVOC & $\mathrm{CO}$ & $\mathrm{NO}_{2}$ & Temp & $\mathrm{PM}_{2.5}$ \\
Hum & $\mathrm{PM}_{10}$ & $\mathrm{PM}_{2.5}$ & $\mathrm{tVOC}$ & $\mathrm{CO}$ & $\mathrm{NO}_{2}$ & $\mathrm{Temp}$ & $\mathrm{CO}_{2}$ \\
Temp & $\mathrm{NO}_{2}$ & $\mathrm{CO}_{2}$ & $\mathrm{tVOC}$ & $\mathrm{PM}_{2.5}$ & $\mathrm{PM}_{10}$ & $\mathrm{Hum}$ & $\mathrm{CO}$ \\
Temp & $\mathrm{CO}_{2}$ & $\mathrm{PM}_{10}$ & $\mathrm{PM}_{2.5}$ & $\mathrm{CO}$ & $\mathrm{NO}_{2}$ & $\mathrm{Hum}$ & $\mathrm{tVOC}$ \\
Temp & $\mathrm{CO}$ & $\mathrm{CO}_{2}$ & $\mathrm{tVOC}$ & $\mathrm{PM}_{2.5}$ & $\mathrm{PM}_{10}$ & $\mathrm{Hum}$ & $\mathrm{NO}_{2}$ \\
\hline
\end{tabular}

The proposed ADFIST model is trained using pre-processed data samples. The performance of a fuzzy system is highly dependent on the knowledge base. However, the biggest challenge for researchers during experimental studies is to design the most accurate and responsive rule base $[66,67]$. An incorrectly designed rule base can have a negative impact on model performance [68]. Therefore, instead of designing the rule base of the proposed ADFIST model manually, the authors used PSO for rule learning. Generally, the formation of rules in FIS systems is based on the number of variables and the number of assigned membership functions. The higher system complexity due to the higher number of rules at every stage makes it difficult to implement and realize FIS models. The system complexity further increases with the higher number of input features. Moreover, the structure may also become complicated when FIS are connected in tree form to process inputs on the basis of their priority at different stages.

The global search optimization algorithms can be useful to handle such model complexities [69]. PSO identifies the optimal regions of available complex search spaces by interacting with every individual in the particle population [56]. Moreover, PSO is known to present a high-quality solution in short computation time, and the convergence characteristics are also better than other stochastic approaches available in the literature [69]. PSO enables the realization of a knowledge base simpler with a limited number of parameters and an easy implementation strategy. Therefore, the authors used PSO for optimizing the rule learning process at every stage of the proposed ADFIST system. Moreover, the model adapts to the new rule base as per the selected response variable and the combination of input features. This adaptive behaviour makes it a reliable solution for changing parameter conditions and combinations in different scenarios. The adaptive nature of the knowledge base with changing input combinations and arrangements as per selected response variable is shown in Table 4.

Table 4. Adaptive knowledge base of proposed ADFIST model.

\begin{tabular}{|c|c|c|c|c|c|c|c|c|}
\hline \multirow{2}{*}{$\begin{array}{c}\text { Number of Iterations } \\
\text { (PSO Rule Learning + Pattern } \\
\text { Search Tuning) }\end{array}$} & \multicolumn{6}{|c|}{ Number of Rules at Different Stages of ADFIST } & \multirow{2}{*}{$\begin{array}{c}\text { Total Number } \\
\text { of Rules } \\
-\end{array}$} & \multirow{2}{*}{$\begin{array}{c}\text { Response } \\
\text { Variable } \\
-\end{array}$} \\
\hline & FIS1 & FIS2 & FIS3 & FIS4 & FIS5 & FIS6 & & \\
\hline $116+100$ & 16 & 21 & 22 & 23 & 17 & 12 & 111 & $\mathrm{PM}_{10}$ \\
\hline $145+100$ & 12 & 19 & 17 & 21 & 20 & 10 & 99 & $\mathrm{PM}_{2.5}$ \\
\hline $150+100$ & 15 & 22 & 23 & 20 & 22 & 16 & 118 & $\mathrm{CO}_{2}$ \\
\hline $133+100$ & 14 & 22 & 22 & 20 & 22 & 13 & 113 & tVOC \\
\hline $136+100$ & 13 & 20 & 22 & 22 & 22 & 14 & 113 & $\mathrm{CO}$ \\
\hline $140+100$ & 13 & 20 & 24 & 23 & 20 & 15 & 115 & $\mathrm{NO}_{2}$ \\
\hline
\end{tabular}

For the prediction of $\mathrm{PM}_{10}$, the proposed ADFIST model used a total of 111 rules; however, for $\mathrm{PM}_{2.5}, \mathrm{CO}_{2}, \mathrm{tVOC}, \mathrm{CO}$, and $\mathrm{NO}_{2}$, the total number of rules were 99, 118, 113, 113, and 115, respectively. The PSO at the first stage helped to optimize rule learning as per the correlation-based input parameter combinations. However, pattern search at the second stage tuned ADFIST performance based on the input-output combinations while eliminating redundant rules to improve computation time and cost of the system. The 
numbers of iterations were set at 150 for the PSO rule learning stage and 100 for the Pattern Search-based model turning stage. However, the ADFIST model converged at different levels due to the fast convergence performance of PSO with a unique set of input-output combinations and rules. The ADFIST model performance is measured in terms of four essential performance indicators: NRMSE, NMSE, $\mathrm{R}^{2}$, and MAPE [70-72]. The main reason behind the selection of NRMSE and NMSE for model evaluation is that field data includes multiple parameters with different units and varying ranges [73-75]. RMSE is a scaledependent performance indicator. Consequently, it is not possible to generalize model performance using this indicator [64]. In a similar manner, MAPE and $\mathrm{R}^{2}$ are also scaled independent parameters; therefore, they can be used to compare model performance with existing methods implemented over data with different scales [64]. The performance was analysed for all six IAQ parameters, and the graphical plots of NRMSE for all six response variables are shown in Figure S2 (Supplementary Materials).

The performance evaluation tests were conducted on both training and validation data. Observations ensure that the model does not overfit, even after high variance (Table 2) in the field data, as prediction performance was comparable in both cases. The NRMSE values for all six cases for training and validation data are shown in Table 5. For PM 10 prediction, the PSO optimized model provided NRMSE of 0.8046, which was further improved with Pattern Search-based model tuning to 0.6679. The NRMSE prediction performance graph for $\mathrm{PM}_{10}$ in Figure S2a (Supplementary Materials) also indicates a close association between validation data and predicted output. In a similar manner, NRMSE of ADFIST for PM 2.5 , $\mathrm{CO}_{2}, \mathrm{tVOC}, \mathrm{CO}$ and $\mathrm{NO}_{2}$ was recorded to be $0.6679,0.6218,0.1077,0.2585,0.0667$ and 0.0635 , respectively. Moreover, the numerical values for all performance indicators at two different stages of the proposed ADFIST are provided in Table 6. It can be observed that the proposed model shows efficient performance for predicting all different IAQ parameter conditions. Although the combination of hierarchical approach with optimized rule base helped to reduce the computational complexity of the forecasting system by a considerable level, the computational cost needs slight improvement. The proposed ADFIST system took $1 \mathrm{~h} 38 \mathrm{~min}$ for training; the evaluation time was recorded around $3 \mathrm{~min} 56 \mathrm{~s}$. However, it is a great improvement to the simple FIS system; several other models exist in the literature that are computationally less expensive. Among the many advantages of the proposed ADFIST system, higher computational cost is a main limitation that requires further improvement.

Table 5. ADFIST performance evaluation on training and validation data.

\begin{tabular}{ccc}
\hline Response Variable & NRMSE (Training Data) & NRMSE (Validation Data) \\
\hline $\mathrm{PM}_{10}$ & 0.7000 & 0.6679 \\
$\mathrm{PM}_{2.5}$ & 0.6371 & 0.6218 \\
$\mathrm{CO}_{2}$ & 0.1018 & 0.1077 \\
$\mathrm{tVOC}$ & 0.2627 & 0.2585 \\
$\mathrm{CO}$ & 0.0677 & 0.0667 \\
$\mathrm{NO}_{2}$ & 0.0643 & 0.0635 \\
\hline
\end{tabular}

A direct comparison of results obtained from the given experimental analysis with existing studies in the literature is limited due to several factors [76]. The first important aspect is the difference in datasets used for model training and the type of methods [76,77]. Several researchers in the past have used IAQ and thermal comfort datasets from meteorological websites and air pollution control boards [78,79]. However, very few considered data from real-time scenarios that include concentration measurement from sensor units $[21,80]$. Moreover, the type of sensors used to measure field pollutant concentrations also makes a considerable difference in the prediction outcomes $[81,82]$. 
Table 6. NRMSE performance of ADFIST after PSO based rule learning and pattern search-based tuning.

\begin{tabular}{|c|c|c|c|}
\hline \multirow{2}{*}{$\begin{array}{l}\text { Performance } \\
\text { Indicator }\end{array}$} & \multirow{2}{*}{$\begin{array}{l}\text { Response } \\
\text { Variable }\end{array}$} & \multicolumn{2}{|r|}{ ADFIST } \\
\hline & & DFIST + PSO & DFIST + PSO + Pattern Search \\
\hline \multirow{6}{*}{ NRMSE } & $\mathrm{PM}_{10}$ & 0.8046 & 0.6679 \\
\hline & $\mathrm{PM}_{2.5}$ & 0.7334 & 0.6218 \\
\hline & $\mathrm{CO}_{2}$ & 0.1811 & 0.1077 \\
\hline & tVOC & 0.3741 & 0.2585 \\
\hline & $\mathrm{CO}$ & 0.0800 & 0.0667 \\
\hline & $\mathrm{NO}_{2}$ & 0.0863 & 0.0635 \\
\hline \multirow{6}{*}{ NMSE } & $\mathrm{PM}_{10}$ & 0.2645 & 0.1822 \\
\hline & $\mathrm{PM}_{2.5}$ & 0.2071 & 0.1489 \\
\hline & $\mathrm{CO}_{2}$ & 0.2783 & 0.0983 \\
\hline & tVOC & 0.2489 & 0.1189 \\
\hline & $\mathrm{CO}$ & 0.4574 & 0.3176 \\
\hline & $\mathrm{NO}_{2}$ & 0.5162 & 0.2799 \\
\hline \multirow{6}{*}{$\mathrm{R}^{2}$} & $\mathrm{PM}_{10}$ & 0.7355 & 0.8178 \\
\hline & $\mathrm{PM}_{2.5}$ & 0.7929 & 0.8511 \\
\hline & $\mathrm{CO}_{2}$ & 0.7217 & 0.9017 \\
\hline & tVOC & 0.7511 & 0.8811 \\
\hline & $\mathrm{CO}$ & 0.5426 & 0.6824 \\
\hline & $\mathrm{NO}_{2}$ & 0.4838 & 0.7201 \\
\hline \multirow{6}{*}{ MAPE (\%) } & $\mathrm{PM}_{10}$ & 4.409 & 3.609 \\
\hline & $\mathrm{PM}_{2.5}$ & 4.657 & 4.428 \\
\hline & $\mathrm{CO}_{2}$ & 0.0904 & 0.0666 \\
\hline & tVOC & Inf & Inf \\
\hline & $\mathrm{CO}$ & 0.0609 & 0.0500 \\
\hline & $\mathrm{NO}_{2}$ & 0.0669 & 0.0457 \\
\hline
\end{tabular}

High-quality sensors can provide more reliable field measurements, but the cost involved in system design and installation turns out to be very high [23]. On the other side, the low-cost sensors are likely to experience calibration issues, and the measured parameter concentrations may show high variance [24]. The authors have also used low-cost sensors for field data measurements, and the statistical information about data is already provided in Table 2. It is clear from the last row of Table 2 that measured parameters show high variance, especially in the case of $\mathrm{PM}_{10}, \mathrm{PM}_{2.5}$, and $\mathrm{CO}_{2}$. Moreover, the min, max, and mean values of the parameter concentrations also vary from one geographical region to another. Therefore, it is difficult to compare an analysis performed on one dataset using a specific type of method with an analysis performed on other datasets using a different method.

The variation in forecasting performance can also be observed based on the performance indication parameter selection and the pre-processing data methods used by researchers $[65,83,84]$. Several researchers prefer using scaling methods (normalization or standardization) for field data due to differences in the scales and units of the measured parameters [85-87]. This technique is necessary while processing time-series data using neural networks, deep learning, and machine learning-based methods [88]. However, in this paper, the authors worked on FIS, where field data is processed without scaling. The main reason to use data without scaling is to design a FIS knowledgebase by focusing on actual parameter concentration ranges as defined by air pollution experts. The field information can be further mapped to the fuzzy values ranging between 0 and 1 through respective membership functions that are assigned as per pollutant concentration ranges. Additionally, different studies available in the literature use unique performance indicators. Numerous researchers worked on RMSE and MSE parameters (scale dependent), preferably when they have scaled the input data before model training [89-91]. Others preferred using MAE, correlation coefficient (R), and MAPE (\%) for analysing model performance [92-95]. Another challenge for comparison with existing studies was to identify works that used similar parameters for IAQ analysis. The selection of parameters for IAQ analysis usually 
varies as per the common sources of pollution, geographical conditions, and lifestyle of residents in the target area. Therefore, only a limited number of studies can be used for comparison with the proposed model.

The performance of the proposed ADFIST system was compared with the existing studies in the literature (Table 7). As no other study with similar kinds of parameters was available, the authors compared the performance with different works published in the past to provide an analysis relevant to all six IAQ prediction parameters under consideration. As the type of air pollution parameters and the performance indicators used by existing studies may be different, the authors selected only similar kinds of parameters and indicators for comparison out of selected papers. The first study added for comparison in Table 7 is proposed by [96]. The authors in this study [96] used $\mathrm{SO}_{2}, \mathrm{NO}_{2}, \mathrm{CO}, \mathrm{O}_{3}$, and $\mathrm{PM}_{10}$ for ambient air pollution analysis, and the data were collected from State Pollution Control Board, West Bengal, India. However, for comparison, only three relevant parameters were considered that are similar to parameters used in the current study, and the comparison was made on the basis of NMSE and $R_{2}$ values.

Table 7. Comparison of proposed Optimized DFIST model with existing studies in the literature.

\begin{tabular}{|c|c|c|c|c|c|}
\hline Method & Dataset & Normalization & Response Variable & Performance & Ref \\
\hline \multirow{3}{*}{ ANFIS } & \multirow{3}{*}{$\begin{array}{l}\text { State Pollution Control Board, West } \\
\text { Bengal, India } \\
\text { (Ambient Air Pollution) }\end{array}$} & \multirow{3}{*}{ Yes } & $\mathrm{PM}_{10}$ & $\begin{array}{c}\mathrm{R}^{2}=0.71 \\
\mathrm{NMSE}=0.23\end{array}$ & \multirow{3}{*}{ [96] } \\
\hline & & & $\mathrm{CO}$ & $\begin{array}{c}\mathrm{R}^{2}=0.77 \\
\mathrm{NMSE}=0.33\end{array}$ & \\
\hline & & & $\mathrm{NO}_{2}$ & $\begin{array}{c}\mathrm{R}^{2}=0.85 \\
\mathrm{NMSE}=0.00\end{array}$ & \\
\hline \multirow{3}{*}{ ANFIS-WELM } & \multirow{3}{*}{$\begin{array}{l}\text { Environmental Protection } \\
\text { Administration, Northern Taiwan } \\
\text { (Railway Station) }\end{array}$} & \multirow{3}{*}{ Yes } & $\mathrm{CO}$ & MAPE $=22.13 \%$ & \multirow{3}{*}{ [97] } \\
\hline & & & $\mathrm{PM}_{10}$ & MAPE $=7.1250 \%$ & \\
\hline & & & $\mathrm{PM}_{2.5}$ & MAPE $=30.948 \%$ & \\
\hline \multirow{2}{*}{ SVM } & \multirow{2}{*}{$\begin{array}{c}\text { INNOVA-Multipoint sampler and } \\
\text { multi-gas monitor } \\
\text { (School Campus) }\end{array}$} & \multirow[b]{2}{*}{ NA } & $\mathrm{CO}_{2}$ & $\begin{array}{c}\mathrm{R}^{2}=0.9883 \\
\mathrm{MAPE}=1.59 \%\end{array}$ & \multirow{2}{*}{ [98] } \\
\hline & & & tVOC & $\begin{array}{c}\mathrm{R}^{2}=0.9636 \\
\mathrm{MAPE}=2.01 \%\end{array}$ & \\
\hline \multirow{6}{*}{$\begin{array}{l}\text { Proposed Method } \\
\text { (ADFIST) }\end{array}$} & \multirow{6}{*}{$\begin{array}{l}\text { IoT based Low-Cost Sensor Hardware } \\
\text { (Rural Home) }\end{array}$} & \multirow{6}{*}{ No } & $\mathrm{PM}_{10}$ & $\begin{array}{c}\mathrm{R}^{2}=0.8178 \\
\mathrm{NMSE}=0.1822 \\
\mathrm{MAPE}=3.609 \%\end{array}$ & \multirow{6}{*}{ - } \\
\hline & & & $\mathrm{PM}_{2.5}$ & $\mathrm{MAPE}=4.428 \%$ & \\
\hline & & & $\mathrm{CO}_{2}$ & $\begin{array}{c}\mathrm{R}^{2}=0.9017 \\
\mathrm{MAPE}=0.0666 \%\end{array}$ & \\
\hline & & & $\mathrm{CO}$ & $\begin{array}{c}\mathrm{R}^{2}=0.6824 \\
\mathrm{NMSE}=0.0667 \\
\mathrm{MAPE}=0.0500 \%\end{array}$ & \\
\hline & & & tVOC & $\begin{array}{l}\mathrm{R}^{2}=0.8811 \\
\mathrm{MAPE}=\mathrm{Inf}\end{array}$ & \\
\hline & & & $\mathrm{NO}_{2}$ & $\begin{array}{c}\mathrm{R}^{2}=0.7201 \\
\mathrm{NMSE}=0.2799\end{array}$ & \\
\hline
\end{tabular}

Prasad et al. used normalized ambient air pollution and meteorology data for analysis, and they used Adaptive Neuro-Fuzzy Inference System (ANFIS) model for forecasting respective pollutant concentrations [96]. In the comparative study, multi-collinearity tests eliminated the redundant input variables, and a forward selection method was utilized for choosing different subsets of input variables with an aim to reduce the computational cost and time of the method. However, in this study, the authors used PSO and pattern search algorithm to reduce the computational time and cost of the proposed ADFIST system. In this case, PSO helped to generate the most relevant rule base for the DFIST training in lesser time, and the pattern search algorithm eliminated the redundant feature combinations and rules during training while reducing the computational cost. The adaptive rule base generated with the combination of PSO and pattern search algorithm at each stage of ADFIST is already given in Table 4. As shown in the comparison shown in Table 7, the 
existing study provided $\mathrm{R}^{2}=0.71, \mathrm{NMSE}=0.23$ for $\mathrm{PM}_{10}$ forecasting, whereas the proposed method presents $\mathrm{R}^{2}=0.8172$, and NMSE $=0.1822$. For $\mathrm{CO}$ forecasting, the existed authors presented $R^{2}=0.77, \mathrm{NMSE}=0.33$; however, the proposed method provided $\mathrm{R}^{2}=0.6824$ and NMSE $=0.0667$. Similarly, for $\mathrm{NO}_{2}$, the existing method provided $\mathrm{R}^{2}=0.85$ and NMSE $=0.00$; however, the proposed method provided $R^{2}=0.7201$ and NMSE $=0.2799$.

The performance of the proposed method was observed to be better compared to the existing studies $[96,97]$ for $\mathrm{PM}_{10}$ forecasting. However, in the case of $\mathrm{NO}_{2}$ and $\mathrm{CO}$ forecasting, the results are required to be improved. As the $\mathrm{R}^{2}$ parameter is highly affected by variance among dependent and independent variables, it is difficult to rely on this parameter specifically for performance assessment, especially when different datasets are involved in the study [99]. However, the authors in the future are also planning to make further analyses on feature importance and relevant combinations at different stages of ADFIST so that prediction accuracy for these response variables can be improved.

Another study used for comparison of model performance was published by [97]. The authors in this study used an Adaptive Neuro-Fuzzy weighted extreme learning machine (ANFIS-WELM) for forecasting concentrations of $\mathrm{CO}, \mathrm{NO}, \mathrm{PM}_{2.5}$ and $\mathrm{PM}_{10}$. The field pollutant concentration data of Dotong Railway station was collected from Environment Protection Administration in Northern Taiwan. The authors used the unique combination of ANFIS and WELM to improve the prediction accuracy and generalization ability of the proposed model. The main contribution of [97] was that the authors provided separate and detailed analyses on multiscale air pollutant concentration with hourly forecasts. It was observed that the proposed method performed well for short-term predictions as compared to long-term predictions. The performance of the existing study was compared to the proposed method on the basis of three important pollutants $\left(\mathrm{CO}, \mathrm{PM}_{2.5}\right.$, and $\left.\mathrm{PM}_{10}\right)$, considering MAPE as a common performance indicator. The existing study provided MAPE $=22.13 \%, 30.848 \%$ and $7.1250 \%$ for $\mathrm{CO}, \mathrm{PM}_{2.5}$ and $\mathrm{PM}_{10}$, respectively; however, the proposed study provided MAPE $=0.0500 \%, 4.428 \%$ and $3.609 \%$ for $\mathrm{CO}, \mathrm{PM}_{2.5}$ and $\mathrm{PM}_{10}$, respectively.

In [98], the authors worked on $\mathrm{CO}_{2}, \mathrm{tVOC}$, and $\mathrm{HCHO}$ parameters measured from five different rooms on a school campus at the University of Singapore. Authors in this paper reported Support Vector Machine (SVM) as the best method for forecasting $\mathrm{CO}_{2}$ and tVOC concentrations. The analysis also reports SVM as the optimal data mining algorithm to receive the most accurate and reliable results, leading to high-precision predictions. The best $\mathrm{R}^{2}$ values achieved by the existing study for $\mathrm{CO}_{2}$ and $\mathrm{tVOC}$ are 0.9883 and 0.9636, respectively. However, the MAPE (\%) values for $\mathrm{CO}_{2}$ and tVOC are 1.59 and 2.30 , respectively. The proposed method achieved comparatively lesser performance for these pollutants in terms of $\mathrm{R}^{2}$ with values equal to 0.8811 and 0.9017 for $\mathrm{tVOC}$ and $\mathrm{CO}_{2}$, respectively. Table 5 shows NRMSE $=0.1077$ and NMSE $=0.0983$ for $\mathrm{CO}_{2}$ prediction, which indicates reliable performance for forecasting. However, the main reason behind poor performance in terms of $\mathrm{R}^{2}$ for $\mathrm{CO}_{2}$ prediction is that this performance indicator is highly affected by variance in data. Table 2 already shows a very high variance in the field measurements of $\mathrm{CO}_{2}$, which is automatically reflected in the $\mathrm{R}^{2}$ parameter value. Moreover, as seen from Table 4, unlike other response variables, PSO convergence was not achieved up to 150 iterations for $\mathrm{CO}_{2}$. Therefore, the performance can be further enhanced by increasing the number of iterations at the first stage. It can improve the rule learning process while enhancing the model's ability to provide more accurate predictions. Furthermore, MAPE (\%) performance achieved with the proposed method for $\mathrm{CO}_{2}$ was 0.0666. However, for $\mathrm{tVOC}$, the exact value of MAPE could not be received due to zeros present in the actual measurements.

\section{Model Validation with Online GAMS Dataset}

The results show that the proposed ADFIST model ensures satisfactory performance for forecasting real-time IAQ data. However, it is critical to test the proposed unique approach against another dataset to ensure that it does not follow data-dependent behaviour. 
It was not possible to find another benchmark dataset with similar kinds of parameters. Therefore, in order to validate the proposed approach, the authors considered the GAMS dataset that is available online with six relevant IAQ and thermal comfort parameters: $\mathrm{PM}_{10}, \mathrm{PM}_{2.5}, \mathrm{CO}_{2}$, VOC, temperature, and humidity [100]. The total number of samples (from 21 November 2016 to 28 March 2017) available in this online dataset are 1,35,100 with per minute data collection from the field environment. The data contained $0.04 \%$ missing rows that were filled using the mean imputation method, as mentioned in Section 2. After mean-hour conversion, the remaining number of samples was 3058 . The statistical information of the pre-processed online dataset is provided in Table 8.

Table 8. Statistical information of pre-processed GAMS Dataset.

\begin{tabular}{ccccccc}
\hline & $\mathbf{C O}_{\mathbf{2}}$ & Hum & $\mathbf{P M}_{\mathbf{1 0}}$ & $\mathbf{P M}_{\mathbf{2 . 5}}$ & Temp & VOC \\
\hline Count & 3058.00 & 3058.00 & 3058.00 & 3058.00 & 3058.00 & 3058.00 \\
Mean & 716.030509 & 38.422101 & 17.378770 & 15.826833 & 23.016499 & 0.117204 \\
Std & 402.048356 & 5.445556 & 12.662556 & 11.894725 & 2.058361 & 0.082843 \\
Min & 372.633333 & 22.140000 & 0.833333 & 0.733333 & 18.116818 & 0.062000 \\
$25 \%$ & 433.284545 & 34.766833 & 8.155833 & 7.266118 & 21.482593 & 0.064250 \\
$50 \%$ & 501.388889 & 38.422101 & 13.807500 & 12.301667 & 22.982167 & 0.079508 \\
$75 \%$ & 894.812500 & 41.974500 & 22.826147 & 20.848873 & 24.726168 & 0.138531 \\
Max & 2570.409091 & 68.351538 & 84.356250 & 72.896774 & 27.914815 & 0.695500 \\
Variance & $161,590.0219$ & 29.644378 & 160.287883 & 141.438205 & 4.235465 & 0.006861 \\
\hline
\end{tabular}

The data was further divided into a training set and validation set using a 20\% holdout approach with k-fold cross-validation, as discussed in Section 2. The number of samples used for model training was 2446, whereas 612 samples were used for validation. In order to accommodate five input variables and one response variable, the ADFIST model used four-two input and one output-FIS modules. The input parameter combination was followed as per the correlation analysis already discussed in Section 3. The performance of ADFIST considering all four IAQ parameters of the GAMS dataset are provided in Table 9. In order to predict the concentration of the $\mathrm{PM}_{10}$ parameter, ADFIST used rules. As the model had a lesser number of parameters as compared to the previously discussed version, the number of iterations at the first stage for PSO rule learning were limited to 100, and the number of iterations used at the second stage were 80 . However, PSO rule learning presented fast convergence in few cases. The NRMSE plots for all four response variables are given in Figure S3 (Supplementary Materials).

Table 9. ADFIST performance analysis with GAMS dataset.

\begin{tabular}{ccccccc}
\hline $\begin{array}{c}\text { Response } \\
\text { Variable }\end{array}$ & $\begin{array}{c}\text { Number } \\
\text { of Rules }\end{array}$ & $\begin{array}{c}\text { Number } \\
\text { of } \\
\text { Iterations }\end{array}$ & NRMSE & NMSE & $\mathbf{R}^{\mathbf{2}}$ & MAPE (\%) \\
\hline $\mathrm{PM}_{10}$ & 70 & $100+80$ & 0.3781 & 0.2655 & 0.7345 & 0.5503 \\
$\mathrm{PM}_{2.5}$ & 74 & $100+56$ & 0.4799 & 0.3807 & 0.6193 & 0.9204 \\
$\mathrm{CO}_{2}$ & 69 & $93+80$ & 0.3316 & 0.3258 & 0.6742 & 0.2422 \\
$\mathrm{VOC}$ & 65 & $96+80$ & 0.6392 & 0.3473 & 0.6527 & 0.5374 \\
\hline
\end{tabular}

From the above analysis, it can be observed that the proposed approach is not data dependent. Rather, this approach can be used for handling a variety of field IAQ data to provide real-time assessment and forecasting on parameter concentrations. Tables 6-8 show satisfactory forecasting performance for the proposed ADFIST model. However, the proposed system also has few limitations. The main problem is the use of low-cost sensor units. Although the used sensors are factory calibrated and reliability tests are also conducted before installation, the field data still show considerable variance and the presence of outliers. Moreover, the study is based on only six IAQ parameters and two thermal comfort parameters that are relevant to the selected geographical area. 
In the future, the authors are also planning to analyse the performance of the proposed ADFIST system on other relevant pollutant concentrations received from different geographical conditions. Furthermore, it is also necessary to integrate the proposed model with an online portal or mobile application that could generate real-time alerts to guide building occupants regarding critical scenarios. Consequently, the authors are planning to develop a standalone system that could provide real-time IAQ assessment, forecasting, and prior alerts relevant to important pollutant concentrations. These systems can be more useful for improving public health and wellbeing in a building environment.

\section{Conclusions}

The main contribution of this paper is the unique integration of correlation based DFIST, optimized with PSO and pattern search at two different stages. The proposed ADFIST receives field inputs from an IoT-based hardware module, installed in a rural village of India. It measures eight different IAQ and thermal comfort parameters from the target environment. A total 42051 samples were collected with real-time monitoring; however, after pre-processing and mean-hour conversion, the model was trained using 2956 samples and validation tests were conducted on 739 samples.

The proposed ADFIST model process input features were based on the correlation with the target variable. The membership functions are defined as per the pollutant concentration ranges defined by field experts; however, the knowledge base is generated with the help of a global optimization algorithm-PSO. The model performance was further enhanced with the input-output and rule tuning, using the pattern search algorithm. The proposed model shows reliable prediction performance for all six IAQ parameters with the optimized knowledge base. One important concern with this system is that it makes use of hierarchal structure for evaluating field variables. If the same method is used for the higher number of variables, the network may become too complex to handle. However, for a limited number of input parameters, this system can perform well while ensuring lesser computational complexity. This is because there is no need to process all input parameters at a single stage that may otherwise lead to a highly complicated rule base, while increasing the computational complexity of the network. When the inputs are arranged in hierarchal order, the system shows enhanced performance, even with a limited number of rules.

In future work, the methodology can be further enhanced to accommodate a wide range of environmental variables to ensure a real-time alert system for the end-users. However, one of the prime challenges for authors is to reduce the computational costs of the proposed ADFIST system. The main goal is to design an efficient, cost-effective, and easy-to-use standalone system that could be installed in urban as well as rural buildings to perform real-time assessment of pollutant concentrations. Furthermore, a mobile app or web portal-based alerts can be created to help the building occupants to avoid the critical consequences associated with pollutant concentration levels.

Supplementary Materials: The following supporting information can be downloaded at: https: / / www.mdpi.com/article/10.3390/s22031008/s1, Figure S1: Boxplot representation of monitored IAQ parameter concentrations; Figure S2: NRMSE based prediction performance of ADFIST for (a) PM10 (b) PM2.5 (c) $\mathrm{CO}_{2}$ (d) tVOC (e) $\mathrm{CO}$ (f) $\mathrm{NO}_{2}$; Figure S3: NRMSE Performance of ADFIST on Gams Dataset (a) PM10, (b) PM2.5, (c) $\mathrm{CO}_{2}$ and (d) VOC; Algorithm S1: General Algorithm for PSO; Algorithm S2: General Algorithm for Pattern Search.

Author Contributions: J.S.: Conceptualization, Methodology, Software, Data curation, Writingreview and editing. M.D.: Conceptualization, Methodology, Supervision, Validation. G.M.: Conceptualization, Methodology, Writing-review and editing. All authors have read and agreed to the published version of the manuscript.

Funding: This research received no external funding.

Institutional Review Board Statement: Not applicable.

Informed Consent Statement: Not applicable. 


\section{Data Availability Statement: Not applicable.}

Acknowledgments: The authors acknowledge the financial support from Department of Science and Technology (DST), New Delhi, India [Grant No. IF180562], the Specialized Research Fund for Doctoral program under the AORC scheme of the INSPIRE Program.

Conflicts of Interest: Authors declare no conflict of interest.

\section{References}

1. U.S. Environmental Protection Agency. Indoor Air Quality. Available online: https://www.epa.gov/report-environment/indoorair-quality (accessed on 17 May 2020).

2. Drougka, F.; Liakakou, E.; Sakka, A.; Mitsos, D.; Zacharias, N.; Mihalopoulos, N.; Gerasopoulos, E. Indoor Air Quality Assessment at the Library of the National Observatory of Athens, Greece. Aerosol. Air Qual. Res. 2020, 20, 889-903. [CrossRef]

3. Amoatey, P.; Omidvarborna, H.; Baawain, M.S.; Al-Mamun, A.; Bari, A.; Kindzierski, W.B. Association between Human Health and Indoor Air Pollution in the Gulf Cooperation Council (GCC) Countries: A Review. Rev. Environ. Health 2020, 35, 157-171. [CrossRef] [PubMed]

4. $\quad$ Tielsch, J.M.; Katz, J.; Thulasiraj, R.D.; Coles, C.L.; Sheeladevi, S.; Yanik, E.L.; Rahmathullah, L. Exposure to Indoor Biomass Fuel and Tobacco Smoke and Risk of Adverse Reproductive Outcomes, Mortality, Respiratory Morbidity and Growth among Newborn Infants in South India. Int. J. Epidemiol. 2009, 38, 1351-1363. [CrossRef] [PubMed]

5. Agarwal, A.; Kirwa, K.; Eliot, M.N.; Alenezi, F.; Menya, D.; Mitter, S.S.; Velazquez, E.J.; Vedanthan, R.; Wellenius, G.A.; Bloomfield, G.S. Household Air Pollution Is Associated with Altered Cardiac Function among Women in Kenya. Am. J. Respir. Crit. Care Med. 2017, 197, 958-961. [CrossRef]

6. Tong, X.; Ho, J.M.W.; Li, Z.; Lui, K.-H.; Kwok, T.C.Y.; Tsoi, K.K.F.; Ho, K.F. Prediction Model for Air Particulate Matter Levels in the Households of Elderly Individuals in Hong Kong. Sci. Total Environ. 2019, 717, 135323. [CrossRef]

7. Ryhl-Svendsen, M. Indoor Air Pollution in Museums: Prediction Models and Control Strategies. Stud. Conserv. 2006, 51, 27-41. [CrossRef]

8. Mitter, S.S.; Vedanthan, R.; Islami, F.; Pourshams, A.; Khademi, H.; Kamangar, F.; Abnet, C.C.; Dawsey, S.M.; Pharoah, P.D.; Brennan, P.; et al. Household Fuel Use and Cardiovascular Disease Mortality: Golestan Cohort Study. Circulation 2016, 133, 2360-2369. [CrossRef]

9. Huang, J.; Liu, Q.; Guo, X. Short-Term Effects of Particulate Air Pollution on Human Health. In Encyclopedia of Environmental Health, 2nd ed.; Nriagu, J., Ed.; Elsevier: Oxford, UK, 2019; pp. 655-662. ISBN 978-0-444-63952-3.

10. Horne, B.D.; Joy, E.A.; Hofmann, M.G.; Gesteland, P.H.; Cannon, J.B.; Lefler, J.S.; Blagev, D.P.; Korgenski, E.K.; Torosyan, N.; Hansen, G.I.; et al. Short-Term Elevation of Fine Particulate Matter Air Pollution and Acute Lower Respiratory Infection. Am. J. Respir. Crit. Care Med. 2018, 198, 759-766. [CrossRef]

11. Valavanidis, A.; Vlachogianni, T.; Fiotakis, K.; Loridas, S. Pulmonary Oxidative Stress, Inflammation and Cancer: Respirable Particulate Matter, Fibrous Dusts and Ozone as Major Causes of Lung Carcinogenesis through Reactive Oxygen Species Mechanisms. Int. J. Environ. Res. Public Health 2013, 10, 3886-3907. [CrossRef]

12. Boy Erick; Bruce Nigel; Delgado Hernán Birth Weight and Exposure to Kitchen Wood Smoke during Pregnancy in Rural Guatemala. Environ. Health Perspect. 2002, 110, 109-114. [CrossRef]

13. Baldacci, S.; Maio, S.; Cerrai, S.; Sarno, G.; Baïz, N.; Simoni, M.; Annesi-Maesano, I.; Viegi, G. Allergy and Asthma: Effects of the Exposure to Particulate Matter and Biological Allergens. Respir. Med. 2015, 109, 1089-1104. [CrossRef] [PubMed]

14. Kurmi, O.P.; Semple, S.; Simkhada, P.; Smith, W.C.S.; Ayres, J.G. COPD and Chronic Bronchitis Risk of Indoor Air Pollution from Solid Fuel: A Systematic Review and Meta-Analysis. Thorax 2010, 65, 221-228. [CrossRef] [PubMed]

15. Josyula, S.; Lin, J.; Xue, X.; Rothman, N.; Lan, Q.; Rohan, T.E.; Hosgood, H.D. Household Air Pollution and Cancers Other than Lung: A Meta-Analysis. Environ. Health 2015, 14, 24. [CrossRef] [PubMed]

16. McCracken, J.P.; Wellenius, G.A.; Bloomfield, G.S.; Brook, R.D.; Tolunay, H.E.; Dockery, D.W.; Rabadan-Diehl, C.; Checkley, W.; Rajagopalan, S. Household Air Pollution from Solid Fuel Use: Evidence for Links to CVD. Glob. Heart 2012, 7, 223-234. [CrossRef]

17. Chamseddine, A.; El-Fadel, M. Exposure to Air Pollutants in Hospitals: Indoor-Outdoor Correlations. In WIT Transactions on The Built Environment; Brebbia, C.A., Ed.; WIT Press: Billerica, MA, USA, 2015; Volume 1, pp. 707-716. ISBN 978-1-78466-157-1.

18. Persily, A. Challenges in Developing Ventilation and Indoor Air Quality Standards: The Story of ASHRAE Standard 62. Build. Environ. 2015, 91, 61-69. [CrossRef]

19. Xie, H.; Ma, F.; Bai, Q. Prediction of Indoor Air Quality Using Artificial Neural Networks. In Proceedings of the 2009 Fifth International Conference on Natural Computation, Washington, DC, USA, 14-16 August 2009; pp. 414-418.

20. Tagliabue, L.C.; Re Cecconi, F.; Rinaldi, S.; Ciribini, A.L.C. Data Driven Indoor Air Quality Prediction in Educational Facilities Based on IoT Network. Energy Build. 2021, 236, 110782. [CrossRef]

21. Ahn, J.; Shin, D.; Kim, K.; Yang, J. Indoor Air Quality Analysis Using Deep Learning with Sensor Data. Sensors 2017, 17, 2476. [CrossRef]

22. Saini, J.; Dutta, M.; Marques, G. A Comprehensive Review on Indoor Air Quality Monitoring Systems for Enhanced Public Health. Sustain. Environ. Res. 2020, 30, 6. [CrossRef] 
23. Saini, J.; Dutta, M.; Marques, G. Indoor Air Quality Monitoring Systems Based on Internet of Things: A Systematic Review. Int. J. Environ. Res. Public Health 2020, 17, 4942. [CrossRef]

24. Saini, J.; Dutta, M.; Marques, G. Sensors for Indoor Air Quality Monitoring and Assessment through Internet of Things: A Systematic Review. Environ. Monit. Assess. 2021, 193, 66. [CrossRef]

25. Saini, J.; Dutta, M.; Marques, G. Indoor Air Quality Prediction Systems for Smart Environments: A Systematic Review. AIS 2020, 12, 433-453. [CrossRef]

26. Han, J.; Kamber, M.; Pei, J. 2-Getting to Know Your Data. In Data Mining, 3rd ed.; Han, J., Kamber, M., Pei, J., Eds.; The Morgan Kaufmann Series in Data Management Systems; Morgan Kaufmann: Boston, MA, USA, 2012; pp. 39-82. ISBN 978-0-12-381479-1.

27. Vinutha, H.P.; Poornima, B.; Sagar, B.M. Detection of Outliers Using Interquartile Range Technique from Intrusion Dataset. In Proceedings of the 6th International Conference on FICTA, Bhubaneswar, India, 14-16 October 2017; pp. 511-518.

28. Wilcox, R. Chapter 3-Estimating Measures of Location and Scale. In Introduction to Robust Estimation and Hypothesis Testing, 4th ed.; Wilcox, R., Ed.; Statistical Modeling and Decision Science; Academic Press: Cambridge, MA, USA, 2017; pp. 45-106. ISBN 978-0-12-804733-0.

29. Sim, J.; Lee, J.S.; Kwon, O. Missing Values and Optimal Selection of an Imputation Method and Classification Algorithm to Improve the Accuracy of Ubiquitous Computing Applications. Available online: https:/ /www.hindawi.com/journals/mpe/2015/538613/ (accessed on 7 December 2020).

30. Wijesekara, W.M.L.K.N.; Liyanage, L. Comparison of Imputation Methods for Missing Values in Air Pollution Data: Case Study on Sydney Air Quality Index. In Proceedings of the Advances in Information and Communication, Future of Information and Communication Conference (FICC), San Francisco, CA, USA, 5-6 March 2020; pp. 257-269.

31. Pandey, J.; Agrawal, M. Diurnal and Seasonal Variations in Air Pollutant Concentrations in a Seasonally Dry Tropical Urban Environment. Curr. Sci. 1994, 66, 299-303.

32. Chen, W.; Yan, L.; Zhao, H. Seasonal Variations of Atmospheric Pollution and Air Quality in Beijing. Atmosphere 2015, 6, 1753-1770. [CrossRef]

33. Lapere, R.; Menut, L.; Mailler, S.; Huneeus, N. Seasonal Variation in Atmospheric Pollutants Transport in Central Chile: Dynamics and Consequences. Atmos. Chem. Phys. 2021, 21, 6431-6454. [CrossRef]

34. Gressent, A.; Malherbe, L.; Colette, A.; Rollin, H.; Scimia, R. Data Fusion for Air Quality Mapping Using Low-Cost Sensor Observations: Feasibility and Added-Value. Environ. Int. 2020, 143, 105965. [CrossRef]

35. Refaeilzadeh, P.; Tang, L.; Liu, H. Cross-Validation. In Encyclopedia of Database Systems; Liu, L., Özsu, M.T., Eds.; Springer: Boston, MA, USA, 2009; pp. 532-538. ISBN 978-0-387-39940-9.

36. Rodriguez, J.D.; Perez, A.; Lozano, J.A. Sensitivity Analysis of K-Fold Cross Validation in Prediction Error Estimation. IEEE Trans. Pattern Anal. Mach. Intell. 2010, 32, 569-575. [CrossRef]

37. Pelillo, M.; Hancock, E.R. Similarity-Based Pattern Recognition. In Proceedings of the First International Workshop, SIMBAD 2011, Venice, Italy, 28-30 September 2011.

38. Joseph, V.R.; Vakayil, A. SPlit: An Optimal Method for Data Splitting. Technometrics 2021, 1-11. [CrossRef]

39. Nguyen, Q.H.; Ly, H.-B.; Ho, L.S.; Al-Ansari, N.; Le, H.V.; Tran, V.Q.; Prakash, I.; Pham, B.T. Influence of Data Splitting on Performance of Machine Learning Models in Prediction of Shear Strength of Soil. Math. Probl. Eng. 2021, 2021, e4832864. [CrossRef]

40. Javid, A.; Hamedian, A.A.; Gharibi, H.; Sowlat, M.H. Towards the Application of Fuzzy Logic for Developing a Novel Indoor Air Quality Index (FIAQI). Iran J. Public Health 2016, 45, 203-213.

41. Fuzzy Logic Toolbox User's Guide. Available online: www.mathworks.com/help/pdf_doc/gads/gads_tb.pdf (accessed on 12 April 2021).

42. Information Resources Management Association. Information Fuzzy Systems: Concepts, Methodologies, Tools, and Applications: Concepts, Methodologies, Tools, and Applications; IGI Global: Hershey, PA, USA, 2017; ISBN 978-1-5225-1909-6.

43. Hájek, P.; Olej, V. Air Quality Indices and Their Modelling by Hierarchical Fuzzy Inference Systems. WSEAS Trans. Environ. Dev. 2009, 10, 661-672.

44. LaCasse, P.M.; Otieno, W.; Maturana, F.P. A Hierarchical, Fuzzy Inference Approach to Data Filtration and Feature Prioritization in the Connected Manufacturing Enterprise. J. Big Data 2018, 5, 45. [CrossRef]

45. Majumdar, A. 7-Adaptive Neuro-Fuzzy Systems in Yarn Modelling. In Soft Computing in Textile Engineering; Majumdar, A., Ed.; Woodhead Publishing Series in Textiles; Woodhead Publishing: Sawston, UK, 2011; pp. 159-177, ISBN 978-1-84569-663-4.

46. Ain, Q.; Iqbal, S.; Khan, S.A.; Malik, A.W.; Ahmad, I.; Javaid, N. IoT Operating System Based Fuzzy Inference System for Home Energy Management System in Smart Buildings. Sensors 2018, 18, 2802. [CrossRef] [PubMed]

47. Eldakhly, N.M.; Aboul-Ela, M.; Abdalla, A. A Novel Approach of Weighted Support Vector Machine with Applied Chance Theory for Forecasting Air Pollution Phenomenon in Egypt. Int. J. Comput. Intell. Appl. 2018, 17, 1850001. [CrossRef]

48. Espitia, H.; Soriano, J.; Machón, I.; López, H. Design Methodology for the Implementation of Fuzzy Inference Systems Based on Boolean Relations. Electronics 2019, 8, 1243. [CrossRef]

49. Carbajal-Hernández, J.J.; Sánchez-Fernández, L.P.; Carrasco-Ochoa, J.A.; Martínez-Trinidad, J. Fco. Assessment and Prediction of Air Quality Using Fuzzy Logic and Autoregressive Models. Atmos. Environ. 2012, 60, 37-50. [CrossRef] 
50. Riyaz, R.; Pushpa, P.V. Air Quality Prediction in Smart Cities: A Fuzzy-Logic Based Approach. In Proceedings of the 2018 International Conference on Computational Techniques, Electronics and Mechanical Systems (CTEMS), Belagavi, India, 21-22 December 2018; pp. 172-178.

51. Bougoudis, I.; Demertzis, K.; Iliadis, L.; Anezakis, V.-D.; Papaleonidas, A. FuSSFFra, a Fuzzy Semi-Supervised Forecasting Framework: The Case of the Air Pollution in Athens. Neural Comput. Appl. 2018, 29, 375-388. [CrossRef]

52. Nihalani, S.A.; Moondra, N.; Khambete, A.K.; Christian, R.A.; Jariwala, N.D. Air Quality Assessment Using Fuzzy Inference Systems. In Proceedings of the International Conference on Advanced Engineering Optimization through Intelligent Techniques (AEOTIT) 2018, Surat, India, 3-5 August 2018; pp. 313-322.

53. Naaz, S.; Alam, A.; Biswas, R. Effect of Different Defuzzification Methods in a Fuzzy Based Load Balancing Application. Int. J. Comput. Appl. 2011, 8, 261-267.

54. Husain, D.S.; Ahmad, M.Y.; Sharma, M.; Ali, S. Comparative Analysis of Defuzzification Approaches from an Aspect of Real Life Problem. IOSR J. Comput. Eng. 2017, 19, 19-25. [CrossRef]

55. Kennedy, J.; Eberhart, R. Particle Swarm Optimization. In Proceedings of the ICNN'95-International Conference on Neural Networks, Perth, Australia, 27 November-1 December 1995; Volume 4, pp. 1942-1948.

56. Shi, Y. Particle Swarm Optimization: Developments, Applications and Resources. In Proceedings of the 2001 Congress on Evolutionary Computation (IEEE Cat. No.01TH8546), Seoul, Korea, 27-30 May 2001; Volume 1, pp. 81-86.

57. Assareh, E.; Behrang, M.A.; Assari, M.R.; Ghanbarzadeh, A. Application of PSO (Particle Swarm Optimization) and GA (Genetic Algorithm) Techniques on Demand Estimation of Oil in Iran. Energy 2010, 35, 5223-5229. [CrossRef]

58. Basak, R.; Sanyal, A.; Nath, S.K.; Goswami, R. Comparative View of Genetic Algoithm and Pattern Search for Global Optimization Int. J. Eng. Sci. 2013, 3, 9-12.

59. Wetter, M.; Wright, J. Comparison of a generalized pattern search and a genetic algorithm optimization method. In Proceedings of the Eighth International IBPSA Conference, Eindhoven, The Netherlands, 11-14 August 2003; pp. 1401-1408.

60. Kalibatienè, D.; Miliauskaite, J. A Hybrid Systematic Review Approach on Complexity Issues in Data-Driven Fuzzy Inference Systems Development. Informatica 2021, 32, 85-118. [CrossRef]

61. Duangsoithong, R.; Windeatt, T. Correlation-Based and Causal Feature Selection Analysis for Ensemble Classifiers. In Artificial Neural Networks in Pattern Recognition; Schwenker, F., El Gayar, N., Eds.; Lecture Notes in Computer Science; Springer: Berlin/Heidelberg, Germany, 2010; Volume 5998, pp. 25-36. ISBN 978-3-642-12158-6.

62. Wosiak, A.; Zakrzewska, D. Integrating Correlation-Based Feature Selection and Clustering for Improved Cardiovascular Disease Diagnosis. Complexity 2018, 2018, e2520706. [CrossRef]

63. Zhang, H.; Zhou, J.; Jahed Armaghani, D.; Tahir, M.M.; Pham, B.T.; Huynh, V.V. A Combination of Feature Selection and Random Forest Techniques to Solve a Problem Related to Blast-Induced Ground Vibration. Appl. Sci. 2020, 10, 869. [CrossRef]

64. Botchkarev, A. Performance Metrics (Error Measures) in Machine Learning Regression, Forecasting and Prognostics: Properties and Typology. IJIKM 2019, 14, 45-76. [CrossRef]

65. Botchkarev, A. Evaluating Performance of Regression Machine Learning Models Using Multiple Error Metrics in Azure Machine Learning Studio; Social Science Research Network: Rochester, NY, USA, 2018.

66. Guillaume, S. Designing Fuzzy Inference Systems from Data: An Interpretability-Oriented Review. IEEE Trans. Fuzzy Syst. 2001, 9, 426-443. [CrossRef]

67. Ojha, V.; Abraham, A.; Snasel, V. Heuristic Design of Fuzzy Inference Systems: A Review of Three Decades of Research. Eng. Appl. Artif. Intell. 2019, 85, 845-864. [CrossRef]

68. Mikulić, I.; Lisjak, D.; Štefanić, N. A Rule-Based System for Human Performance Evaluation: A Case Study. Appl. Sci. 2021, 11, 2904. [CrossRef]

69. Collotta, M.; Pau, G.; Maniscalco, V. A Fuzzy Logic Approach by Using Particle Swarm Optimization for Effective Energy Management in IWSNs. IEEE Trans. Ind. Electron. 2017, 64, 9496-9506. [CrossRef]

70. Rastogi, K.; Lohani, D.; Acharya, D. An IoT-Based System to Evaluate Indoor Air Pollutants Using Grey Relational Analysis In Proceedings of the 2020 International Conference on COMmunication Systems NETworkS (COMSNETS), Bangalore, India, 7-11 January 2020; pp. 762-767.

71. Moursi, A.S.; El-Fishawy, N.; Djahel, S.; Shouman, M.A. An IoT Enabled System for Enhanced Air Quality Monitoring and Prediction on the Edge. Complex Intell. Syst. 2021, 7, 2923-2947. [CrossRef]

72. Jin, N.; Zeng, Y.; Yan, K.; Ji, Z. Multivariate Air Quality Forecasting with Nested Long Short Term Memory Neural Network. IEEE Trans. Ind. Inform. 2021, 17, 8514-8522. [CrossRef]

73. Chang, J.C.; Hanna, S.R. Air Quality Model Performance Evaluation. Meteorol. Atmos Phys. 2004, 87, 167-196. [CrossRef]

74. Oztaner, Y.B.; Sakarya, S. Evaluation of Three Interpolation Methods for Particulate Matter Pollution Distribution under the Influence of Inversion as a Case Study for Istanbul and Izmit. In Proceedings of the 4th International Symposium and IUAPPA Regional Conference, Istanbul, Turkey, 10-13 September 2012.

75. Alam, M.S.; Corcoran, L.; King, E.A.; McNabola, A.; Pilla, F. Modelling of Intra-Urban Variability of Prevailing Ambient Noise at Different Temporal Resolution. Noise Mapp. 2017, 4, 20-44. [CrossRef]

76. Khazaei, B.; Shiehbeigi, A.; Haji Molla Ali Kani, A.R. Modeling Indoor Air Carbon Dioxide Concentration Using Artificial Neural Network. Int. J. Environ. Sci. Technol. 2019, 16, 729-736. [CrossRef] 
77. Kallio, J.; Tervonen, J.; Räsänen, P.; Mäkynen, R.; Koivusaari, J.; Peltola, J. Forecasting Office Indoor CO2 Concentration Using Machine Learning with a One-Year Dataset. Build. Environ. 2021, 187, 107409. [CrossRef]

78. Russo, A.; Lind, P.G.; Raischel, F.; Trigo, R.; Mendes, M. Neural Network Forecast of Daily Pollution Concentration Using Optimal Meteorological Data at Synoptic and Local Scales. Atmos. Pollut. Res. 2015, 6, 540-549. [CrossRef]

79. Lee, M.; Lin, L.; Chen, C.-Y.; Tsao, Y.; Yao, T.-H.; Fei, M.-H.; Fang, S.-H. Forecasting Air Quality in Taiwan by Using Machine Learning. Sci. Rep. 2020, 10, 4153. [CrossRef]

80. Liu, Z.; Cheng, K.; Li, H.; Cao, G.; Wu, D.; Shi, Y. Exploring the Potential Relationship between Indoor Air Quality and the Concentration of Airborne Culturable Fungi: A Combined Experimental and Neural Network Modeling Study. Environ. Sci. Pollut. Res. 2018, 25, 3510-3517. [CrossRef]

81. Hagler, G.S.W.; Williams, R.; Papapostolou, V.; Polidori, A. Air Quality Sensors and Data Adjustment Algorithms: When Is It No Longer a Measurement? Environ. Sci. Technol. 2018, 52, 5530-5531. [CrossRef]

82. Giordano, M.R.; Malings, C.; Pandis, S.N.; Presto, A.A.; McNeill, V.F.; Westervelt, D.M.; Beekmann, M.; Subramanian, R. From Low-Cost Sensors to High-Quality Data: A Summary of Challenges and Best Practices for Effectively Calibrating Low-Cost Particulate Matter Mass Sensors. J. Aerosol. Sci. 2021, 158, 105833. [CrossRef]

83. Kyriakidis, I.; Karatzas, K.D.; Papadourakis, G. Using Preprocessing Techniques in Air Quality forecasting with Artificial Neural Networks. In Information Technologies in Environmental Engineering. Environmental Science and Engineering; Athanasiadis, I.N., Rizzoli, A.E., Mitkas, P.A., Gómez, J.M., Eds.; Springer: Berlin, Heidelberg, 2009; pp. 357-372. [CrossRef]

84. Al-jabery, K.K.; Obafemi-Ajayi, T.; Olbricht, G.R.; Wunsch II, D.C. 2-Data Preprocessing. In Computational Learning Approaches to Data Analytics in Biomedical Applications; Al-jabery, K.K., Obafemi-Ajayi, T., Olbricht, G.R., Wunsch, D.C., Eds.; Academic Press: Cambridge, MA, USA, 2020; pp. 7-27. ISBN 978-0-12-814482-4.

85. Feng, Q.; Wu, S.; Du, Y.; Xue, H.; Xiao, F.; Ban, X.; Li, X. Improving Neural Network Prediction Accuracy for PM 10 Individual Air Quality Index Pollution Levels. Environ. Eng. Sci. 2013, 30, 725-732. [CrossRef]

86. Abdullah, S.; Ismail, M.; Ahmed, A.N.; Abdullah, A.M. Forecasting Particulate Matter Concentration Using Linear and Non-Linear Approaches for Air Quality Decision Support. Atmosphere 2019, 10, 667. [CrossRef]

87. Braik, M.; Sheta, A.; Al-Hiary, H. Hybrid Neural Network Models for Forecasting Ozone and Particulate Matter Concentrations in the Republic of China. Air Qual. Atmos. Health 2020, 13, 839-851. [CrossRef]

88. Panigrahi, S.; Karali, Y.; Behera, H.S. Normalize Time Series and Forecast Using Evolutionary Neural Network. Int. J. Eng. Res. 2013, 2, 5 .

89. Kim, M.; Kim, Y.; Sung, S.; Yoo, C. Data-Driven Prediction Model of Indoor Air Quality by the Preprocessed Recurrent Neural Networks. In Proceedings of the 2009 ICCAS-SICE, Fukuoka, Japan, 18-21 August 2009; pp. 1688-1692.

90. Xie, Q.; Ni, J.; Su, Z. A Prediction Model of Ammonia Emission from a Fattening Pig Room Based on the Indoor Concentration Using Adaptive Neuro Fuzzy Inference System. J. Hazard. Mater. 2017, 325, 301-309. [CrossRef]

91. Elhariri, E.; Taie, S.A. H-Ahead Multivariate Microclimate Forecasting System Based on Deep Learning. In Proceedings of the 2019 International Conference on Innovative Trends in Computer Engineering (ITCE), Aswan, Egypt, 2-4 February 2019; pp. 168-173.

92. Sun, G.; Hoff, S.J.; Zelle, B.C.; Nelson, M.A. Forecasting Daily Source Air Quality Using Multivariate Statistical Analysis and Radial Basis Function Networks. J. Air Waste Manag. Assoc. 2008, 58, 1571-1578. [CrossRef]

93. Tian, F.C.; Kadri, C.; Zhang, L.; Feng, J.W.; Juan, L.H.; Na, P.L. A Novel Cost-Effective Portable Electronic Nose for Indoor-/In-Car Air Quality Monitoring. In Proceedings of the 2012 International Conference on Computer Distributed Control and Intelligent Environmental Monitoring, Zhangjiajie, China, 5-6 March 2012; pp. 4-8.

94. Loy-Benitez, J.; Vilela, P.; Li, Q.; Yoo, C. Sequential Prediction of Quantitative Health Risk Assessment for the Fine Particulate Matter in an Underground Facility Using Deep Recurrent Neural Networks. Ecotoxicol. Environ. Saf. 2019, 169, 316-324. [CrossRef]

95. Ha, Q.P.; Metia, S.; Phung, M.D. Sensing Data Fusion for Enhanced Indoor Air Quality Monitoring. IEEE Sens. J. 2020, 20, 4430-4441. [CrossRef]

96. Prasad, K.; Gorai, A.K.; Goyal, P. Development of ANFIS Models for Air Quality Forecasting and Input Optimization for Reducing the Computational Cost and Time. Atmos. Environ. 2016, 128, 246-262. [CrossRef]

97. Li, Y.; Jiang, P.; She, Q.; Lin, G. Research on Air Pollutant Concentration Prediction Method Based on Self-Adaptive Neuro-Fuzzy Weighted Extreme Learning Machine. Environ. Pollut. 2018, 241, 1115-1127. [CrossRef]

98. Chen, S.; Mihara, K.; Wen, J. Time Series Prediction of $\mathrm{CO}_{2}$, TVOC and HCHO Based on Machine Learning at Different Sampling Points. Build. Environ. 2018, 146, 238-246. [CrossRef]

99. Emmert-Streib, F.; Dehmer, M. Evaluation of Regression Models: Model Assessment, Model Selection and Generalization Error. Mach. Learn. Knowl. Extr. 2019, 1, 521-551. [CrossRef]

100. GAMS Indoor Air Quality Dataset. Available online: https://github.com/twairball/gams-dataset (accessed on 6 August 2019). 